\title{
Prevalence of drug-resistant pulmonary tuberculosis in India: systematic review and meta-analysis
}

\author{
Vishal Goyal, Vijay Kadam*, Prashant Narang and Vikram Singh
}

\begin{abstract}
Background: Drug-resistant pulmonary tuberculosis (DR-TB) is a significant public health issue that considerably deters the ongoing TB control efforts in India. The purpose of this review was to investigate the prevalence of DRTB and understand the regional variation in resistance pattern across India from 1995 to 2015, based on a large body of published epidemiological studies.

Methods: A systematic review of published studies reporting prevalence of DR-TB from biomedical databases (PubMed and IndMed) was conducted. Meta-analysis was performed using random effects model and the pooled prevalence estimate (95\% confidence interval [CI]) of DR-TB, multidrug resistant (MDR-) TB, pre-extensively drugresistant (pre-XDR) TB and XDR-TB were calculated across two study periods (decade 1: 1995 to 2005; decade 2: 2006 to 2015), countrywide and in different regions. Heterogeneity in this meta-analysis was assessed using $I^{2}$ statistic.
\end{abstract}

Results: A total of 75 of 635 screened studies that fulfilled the inclusion criteria were selected. Over $40 \%$ of 45,076 isolates suspected for resistance to any first-line anti-TB drugs tested positive. Comparative analysis revealed a worsening trend in DR-TB between the two study decades (decade 1: $37.7 \%[95 \% \mathrm{Cl}=29.0 ; 46.4], n=25$ vs decade 2: $46.1 \%$ [95\% Cl $=39.0 ; 53.2], n=36)$. The pooled estimate of MDR-TB resistance was higher in previously treated patients (decade 1: $29.8 \%$ [95\% Cl $=20.7 ; 39.0], n=13$; decade 2: 35.8\% [95\% Cl $=29.2 ; 42.4], n=24$ ) as compared with the newly diagnosed cases (decade 1: $4.1 \%[95 \% \mathrm{Cl}=2.7 ; 5.6], \mathrm{n}=13$; decade $2: 5.6 \%[95 \% \mathrm{Cl}=3.8 ; 7.4]$, $n=17)$. Overall, studies from Western states of India reported highest prevalence of DR-TB $(57.8 \%[95 \% \mathrm{Cl}=37.4$; 78.2], $n=6)$ and MDR-TB (39.9\% [95\% $\mathrm{Cl}=21.7 ; 58.0], \mathrm{n}=6)$ during decade 2. Prevalence of pre-XDR TB was 7.9\% $(95 \% \mathrm{Cl}=4.4 ; 11.4, n=5)$ with resistance to fluoroquinolone $(66.3 \%[95 \% \mathrm{Cl}=58.2 ; 74.4], \mathrm{n}=5)$ being the highest. The prevalence of XDR-TB was $1.9 \%(95 \% \mathrm{Cl}=1.2 ; 2.6, n=14)$ over the 20-year period.

Conclusion: The alarming increase in the trend of anti-TB drug resistance in India warrants the need for a structured nationwide surveillance to assist the National TB Control Program in strengthening treatment strategies for improved outcomes.

Keywords: Drug-resistant tuberculosis, India, Prevalence

\footnotetext{
* Correspondence: vkadam8@|TS.JNJ.com

Medical Affairs, Janssen India, Johnson \& Johnson Pvt Ltd., Arena Space, 8th

floor, Off JVLR, Jogeshwari (E), Mumbai 400060, India
} 


\section{Background}

Accelerated tuberculosis (TB) control efforts have been threatened by the emergence of Mycobacterium tuberculosis strains that are resistant to potent first-line drugs (drug resistant tuberculosis or DR-TB) [1-3]. In 2015, the World Health Organization (WHO) estimated 480,000 incident multidrug resistant TB (MDR-TB; resistance of both isoniazid and rifampicin) cases globally. With an estimated 79,000 MDR-TB cases, India along with the Russian Federation and South Africa accounted for $45 \%$ of the total notified combined MDR-TB and rifampicin-resistant (RR-TB) cases in 2015 [4].

The management of DR-TB is critical and based on laboratory confirmation of $\mathrm{TB}$ and a clear understanding of drug resistance aided by drug susceptibility testing (DST) to ensure accurate diagnosis and early intervention of appropriate treatment $[1,3,5]$. Currently, the WHO recommended treatment strategy for complex MDR-TB comprises of a minimum of 5 drugs (including an injectable aminoglycoside) and a protracted treatment period of 18 to 24 months [1, 2]. However, only $50 \%$ of patients worldwide with MDR-TB achieve successful completion of treatment, partially owing to high death rates $(250,000$ [range, 16,000-340,000] estimated deaths from MDR-TB/RR-TB in 2015) and loss to follow-up $[2,4,6]$. In India, only $46 \%$ patients with MDR-TB have been reported to achieve treatment success in 2015 (vs 48\% patients who achieved treatment success in 2014) with $20 \%$ each of death and lost to followup $[7,8]$. Further, worsening outcome of extensively drug-resistant TB (XDR-TB; resistance to at least one fluoroquinolone and injectable aminoglycoside in addition to MDR-TB) has been reported in $9.5 \%$ patients with MDR-TB in 2015 [4].

Prevention and control of drug resistance is therefore strongly recommended by the WHO through implementation of routine surveillance systems driven by systematic DST [3, 9, 10]. Nationwide survey conducted in representative populations using standardized patient stratification and employing quality-assured rapid diagnostic methods are fundamental to a strengthened surveillance [9]. The Revised National Tuberculosis Control Programme (RNTCP) endorses the WHO recommended Directly Observed Treatment, Short course (DOTS) and systematic surveillance in India. This initiative was introduced in 1997 and achieved nationwide coverage in 2006 [8, 11]. Improvements in RNTCP surveillance approach have been noted in the recent years and India accounted for $27 \%$ of the global TB notifications in 2014 (12\% from private sectors) [3, 12]. However, India remains one of the six countries with an enormous MDRTB burden that failed to implement a nationwide drugresistance surveillance (DRS) and relies largely on a subnational evaluation approach $[3,8]$.
Currently, published studies have reported the prevalence of DR-TB from region-specific data obtained from city or state government health facilities or private setups. Epidemiological interpretations from these studies are challenged by large variations in research methodology, patient selection, diagnostic methods, unclear definitions of retreatment as well as data analysis and reporting. Further, till date, there has been no attempt to consolidate these studies to derive pooled prevalence estimates of DR-TB and stratify the prevalence based on geographical distribution. The present study was therefore designed to provide pooled estimates for DR-TB (MDR$\mathrm{TB}$, pre-XDR and XDR-TB) in India through systematic review and meta-analysis of published studies conducted across two decades (1995 to 2015).

\section{Methods}

\section{Search strategy}

Published studies of DR-TB in India were searched using the National Library of Medicine's database, PubMed. Free text and index terms (Medical Subject Headings) related to DR-TB, India and prevalence were used and a wide search strategy was employed to maximize retrieval of relevant articles. Using elements of PICO, the following search terms were identified, Population: patients from India (India); Outcome: prevalence of drug resistant tuberculosis (prevalence, incidence, epidemiology, tuberculosis, Mycobacterium tuberculosis, drug resistant tuberculosis, multidrug resistant tuberculosis, MDR-TB, extensively drug resistant tuberculosis, XDR-TB, antituberculosis drug resistance, totally drug-resistant tuberculosis, TDR-TB). Published articles indexed only in the Indian database IndMed (http://indmed.nic.in/) and not in PubMed were retrieved using similar search terms. To maximize search results, bibliographies of other reviews and original studies were searched manually for additional relevant studies.

\section{Definitions, data extraction, and analysis}

The term drug resistance or DR-TB was used for monodrug resistance (resistance to one first-line antitubercular drug only) and poly-drug resistance (resistance to more than one first-line anti-TB drug other than both isoniazid and rifampicin). Multidrug resistance or MDR-TB was defined as TB with resistance to at least both isoniazid and rifampicin. Pre-XDR was referred to as multidrug resistance along with resistance to a fluoroquinolone or second-line injectable agent but not both. Finally, resistance to any fluoroquinolone and at least one of three second-line injectable drugs (capreomycin, kanamycin and amikacin), in addition to multidrug resistance was referred to as extensively drug resistance or XDR-TB. Previously treated patients included those receiving $\geq 1$ month of anti-TB drugs in the past and newly 
diagnosed patients were those who were never treated for TB or had taken anti-TB drugs for less than 1 month.

The list of articles with studies conducted within decades 1995 to 2005 and 2006 to 2015 retrieved from the two databases were screened and selected manually based on title and abstract to identify relevant studies for inclusion. Once the initial overview was completed, critical literature appraisal of the relevant articles based on the abstract or full-text was performed by a specifically developed data evaluation spreadsheet. Key items included in the spreadsheet were: region of sample origin (including city or state), study period, prevalence of DRTB (including MDR-TB, pre-XDR and XDR-TB), casewise prevalence of DR-TB (newly diagnosed or previously treated or any other type as specified in individual studies), pattern of drug resistance (mono- and combined drug resistance), HIV status and diagnostic techniques used for detection of drug susceptibility (phenotypic or genotypic techniques). A substantial degree of variability in research methodology with respect to patient selection and calculation of prevalence of drug resistance was noted. Calculation of prevalence of DR, MDR (all cases, previously treated, new and combined), pre-XDR and XDR for individual studies were performed using the following standard formulae to maintain uniformity and to assist interpretation.

\footnotetext{
\%prevalence of DR/MDR/pre-XDR/XDR-TB

Number of cases (DR/MDR/pre-XDR/XDR-TB

Total number of M.tuberculosis isolates available for drug susceptibility testing $\times 100$
}

For prevalence of previously treated and newly diagnosed cases of MDR, pre-XDR and XDR-TB, the number of previously treated or newly diagnosed $M$. tuberculosis (MTB) isolates were considered.

The studies were stratified based on predefined variables to understand variations in prevalence estimates. The subgroup analysis was performed on the following variables: 1) By decade: decade 1 (1995 to 2005), period during the initial years of RNTCP implementation and decade 2 (2006 to 2015), period during which RNTCP achieved national coverage 2) By region: North India included states, Jammu and Kashmir, Himachal Pradesh, Punjab, Uttaranchal, Haryana, Delhi, Rajasthan, Uttar Pradesh, Bihar and Jharkhand; South India: Andhra Pradesh, Karnataka, Kerala and Tamil Nadu; West India: Gujarat, Maharashtra and Goa; East and central India: West Bengal, Orissa, all north-eastern states, Chhattisgarh and Madhya Pradesh.

\section{Eligibility}

Studies were considered eligible for inclusion based on the following criteria: (1) specifically reporting the prevalence of pulmonary DR-TB, including breakdown by type of DR-TB (MDR-TB, pre-XDR or XDR-TB) in a population, subgroup or community exclusively from India (2) reporting detection of DR-TB by phenotypic or genotypic assays and suggestive of trends in resistance patterns for anti-TB drugs in isolates of MTB (3) conducted during the years 1995 to 2015.

Articles not published in English and not reporting epidemiology data on DR-TB were excluded. Additionally, the following studies were excluded: (1) reporting prevalence data on non-Indian populations or multicenter studies in which separation of Indian population's DR-TB status was not possible (2) comparing or validating diagnostic tests for DR-TB detection and treatment outcomes or studies on gene mutation profiling with no epidemiological impact (3) reporting both pulmonary and extra pulmonary TB cases wherein isolation of pulmonary data was not possible (4) involving an exclusively human immunodeficiency virus (HIV) co-infected population. Case studies, editorials, author responses, commentaries and general reviews and expert opinions (to avoid duplication) were also excluded.

\section{Statistical analysis}

Meta-analysis was undertaken using random effects model and the pooled estimate for the prevalence of drug resistance along with 95\% CI were calculated. Subgroup analyses were used to understand the potential influences on prevalence estimates. Prevalence estimates were compared descriptively by decade, region and type of resistance (previously treated or newly diagnosed) [13]. Heterogeneity among studies was quantified using the $\mathrm{I}^{2}$ statistic. An $\mathrm{I}^{2}$ value of $0 \%$ indicates no observed heterogeneity whereas, higher values signify increasing heterogeneity. The negative values of $\mathrm{I}^{2}$ were set to zero in order to get all values between $0 \%$ and 100\% [14]. All analyses were performed using SAS version 9.4.

\section{Results}

Summary of literature search

The literature search identified a total of 635 articles (PubMed, $n=367$; Indian database, $n=268$ ) of which based on the inclusion and exclusion criteria, a total 75 articles from both databases (PubMed, $n=62$; Indian database, $n=13$ ) were included in this review (Fig. 1).

\section{Summary of key study characteristics}

Characteristics of the 75 articles included are summarized in Table 1. North India had the largest number of studies $(n=32)$, followed by South India $(n=25)$, West India $(n=12)$, East India $(n=4)$ and Central India $(n=2)$. The results from East and Central regions were combined and populated together for the subgroup analysis, due to smaller number of studies.

Drug resistance (including DR-TB, MDR, pre-XDR and XDR) was reported by 26 studies for a total of 


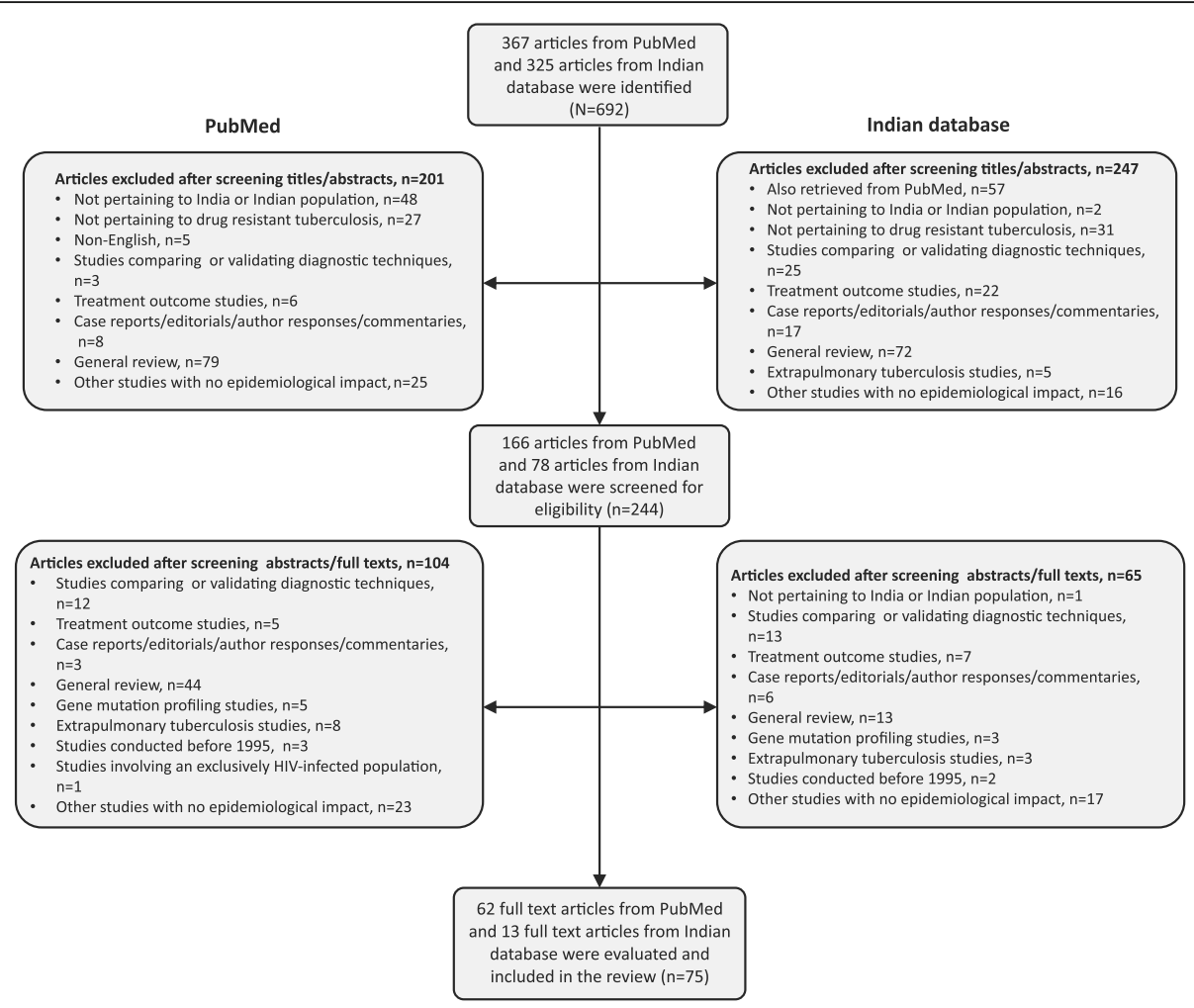

Fig. 1 Flow diagram for selection of studies

20,695 MTB isolates during the decade 1 and by 49 studies for 24,381 MTB isolates in the decade 2. Of these total isolates subjected to drug susceptibility testing (DST), 23,279 (51.6\%) isolates were from previously treated patients and 11,401 (25.3\%) from newly diagnosed cases (includes studies exclusively reporting previously treated and newly diagnosed isolate numbers and those reporting combined isolate numbers with a breakup by category). The remaining 10,396 (23.1\%) were isolates from combined cases (wherein a break-up of isolate number from previously treated and new cases were not available).

The Jain SK et al., 2015 study [15] from West India was considered as an outlier and excluded from analysis due to insufficient sample. The prevalence of DR-TB was found to be higher in the more recent study decade (decade 2 ), with $77.8 \%$ of published studies (28/36 studies) reporting a prevalence rate of more than $20 \%$, as compared to $60.0 \%$ studies (15/25 studies) conducted during decade 1 (Fig. 2). This increasing trend in prevalence across the two decades was also noted for MDRTB. Among studies conducted in decade 2, a prevalence of $>20 \%$ was reported for $44.9 \%$ (22/49) studies versus $20.8 \%(5 / 24)$ studies in decade 1 (Fig. 2). Overall, of the 75 studies included in this analysis that tested 45,076 isolates for possible suspicion of resistance for various reasons, over $40 \%$ isolates were confirmed positive for resistance to any of the first-line anti-TB drugs.

\section{Subgroup analysis (decade and region-wise) for the prevalence of DR-TB and MDR-TB}

The countrywide estimates for DR-TB was 37.7\% (95\% $\mathrm{CI}=29.0 ; 46.4, n=25)$ during decade 1 , and a higher prevalence of $46.1 \%$ (95\% CI $=39.0 ; 53.2, n=36$ ) was reported in decade 2 . Overall, the prevalence estimate over the 20 -year study period was $42.6 \%$ (95\% CI $=37.2$; 48.0, $n=61$ ) (Table 2). The prevalence of DR-TB was highest in South India $(42.1 \%$ [95\% CI $=28.5 ; 55.7, n=11])$ and lowest in the Western region $(31.2 \%$ [95\% CI $=12.6$; 49.8, $n=5]$ ) during decade 1 (Fig. 3). In decade 2, West India $(57.8 \%$ [95\% CI $=37.4 ; 78.2, n=6])$ had the highest prevalence of DR-TB cases, and North India reported the lowest (37.9\% [95\% CI $=30.0 ; 45.7, n=16])$. The countrywide prevalence of MDR-TB also increased from the earlier decade $(14.9 \%$ [95\% CI $=11.0 ; 18.7, n=24]$ ) to decade $2(27.9 \%$ [95\% CI $=23.8 ; 32.1, n=49])$ and the prevalence for the 20-year period was $23.3 \%$ (95\% $\mathrm{CI}=20.5 ; 26.1, n=73$ ) (Table 2). MDR-TB, was most prevalent in the northern states $(18.3 \%$ [95\%CI $=10.9$; 25.6, $n=6])$ and least in the central and eastern states (4.0\% [95\% CI $=-0.9 ; 8.8, n=3])$ during decade 1 (Fig. 3). Whereas, in decade 2, West India reported 


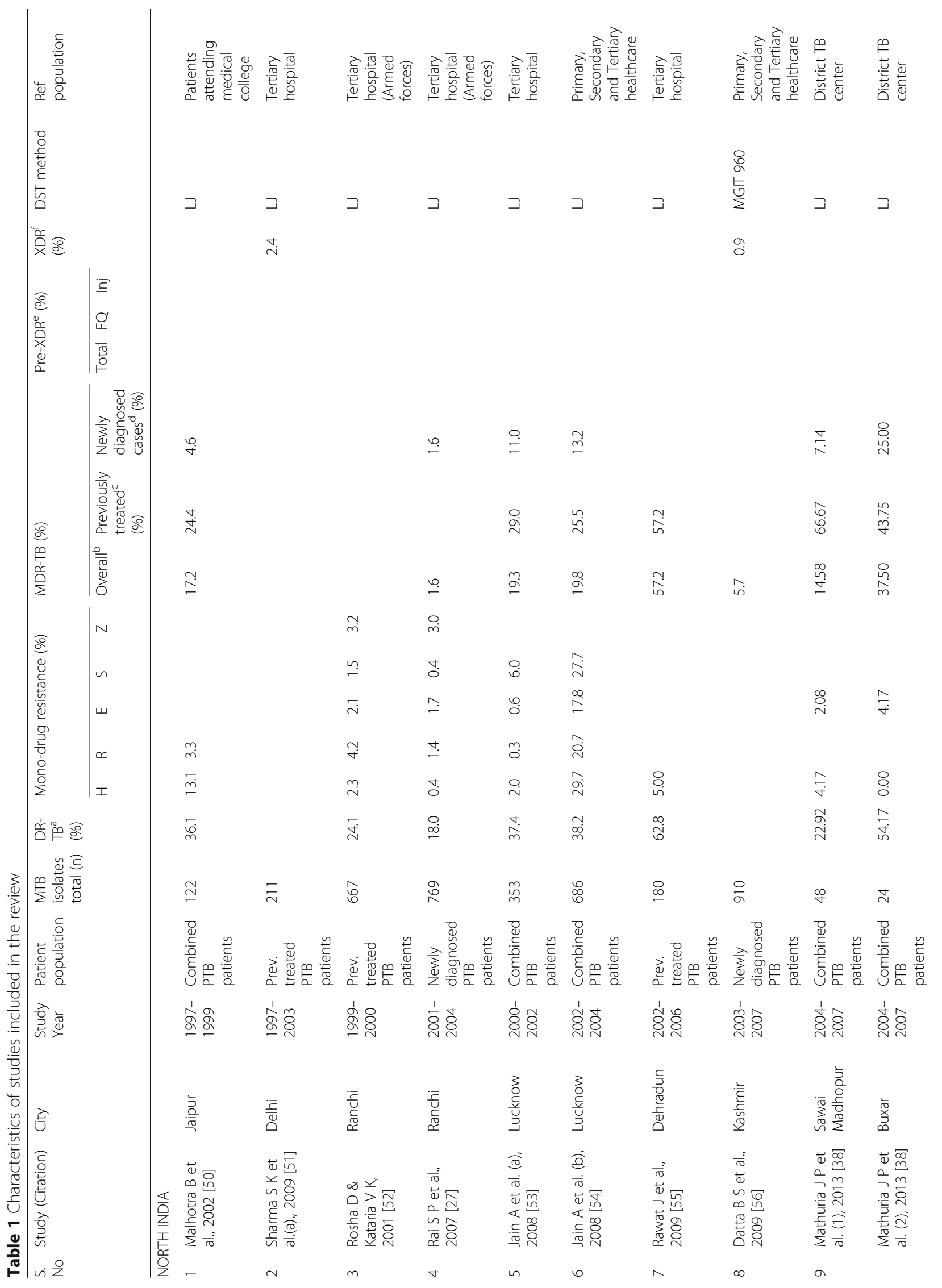




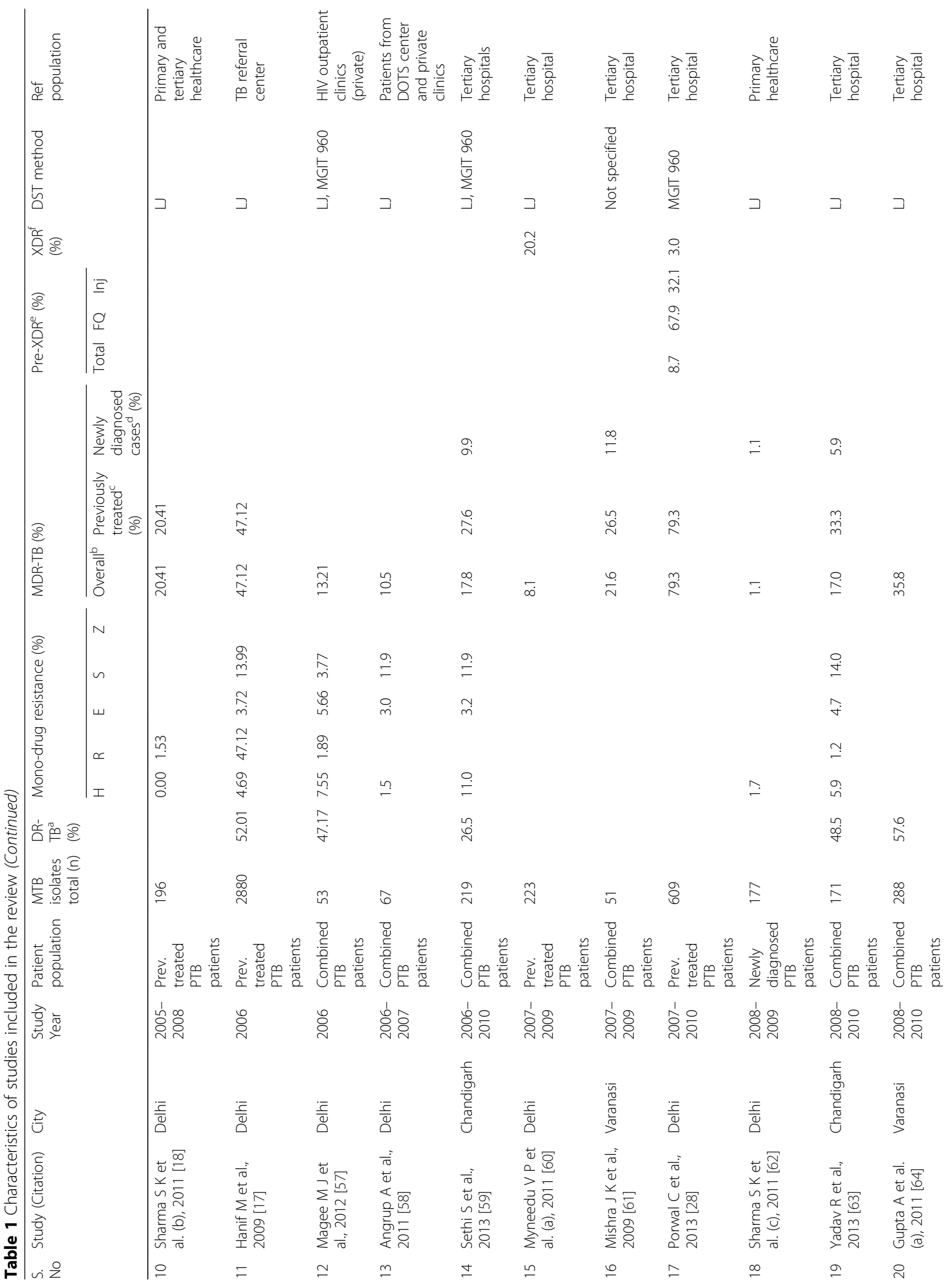




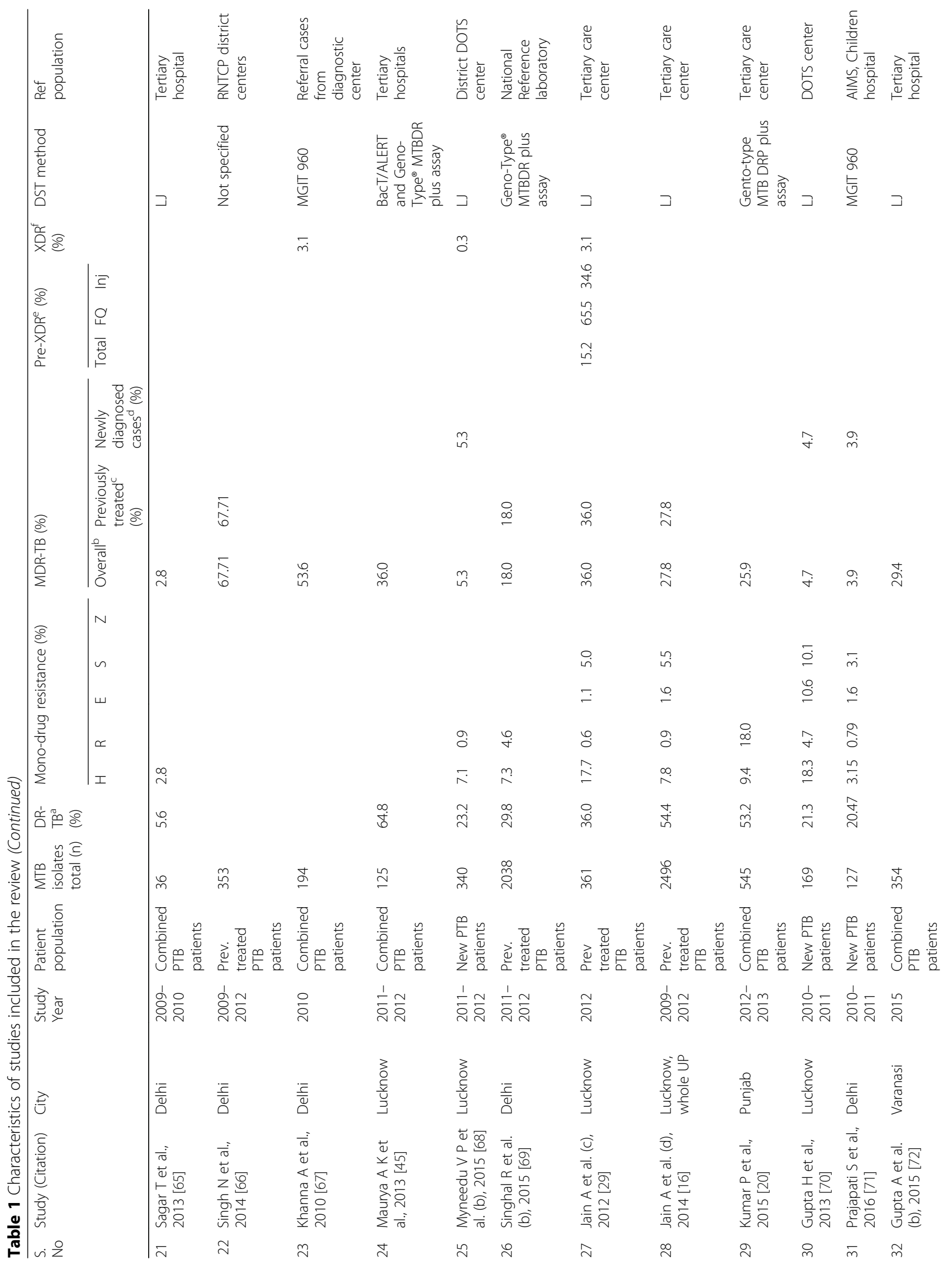




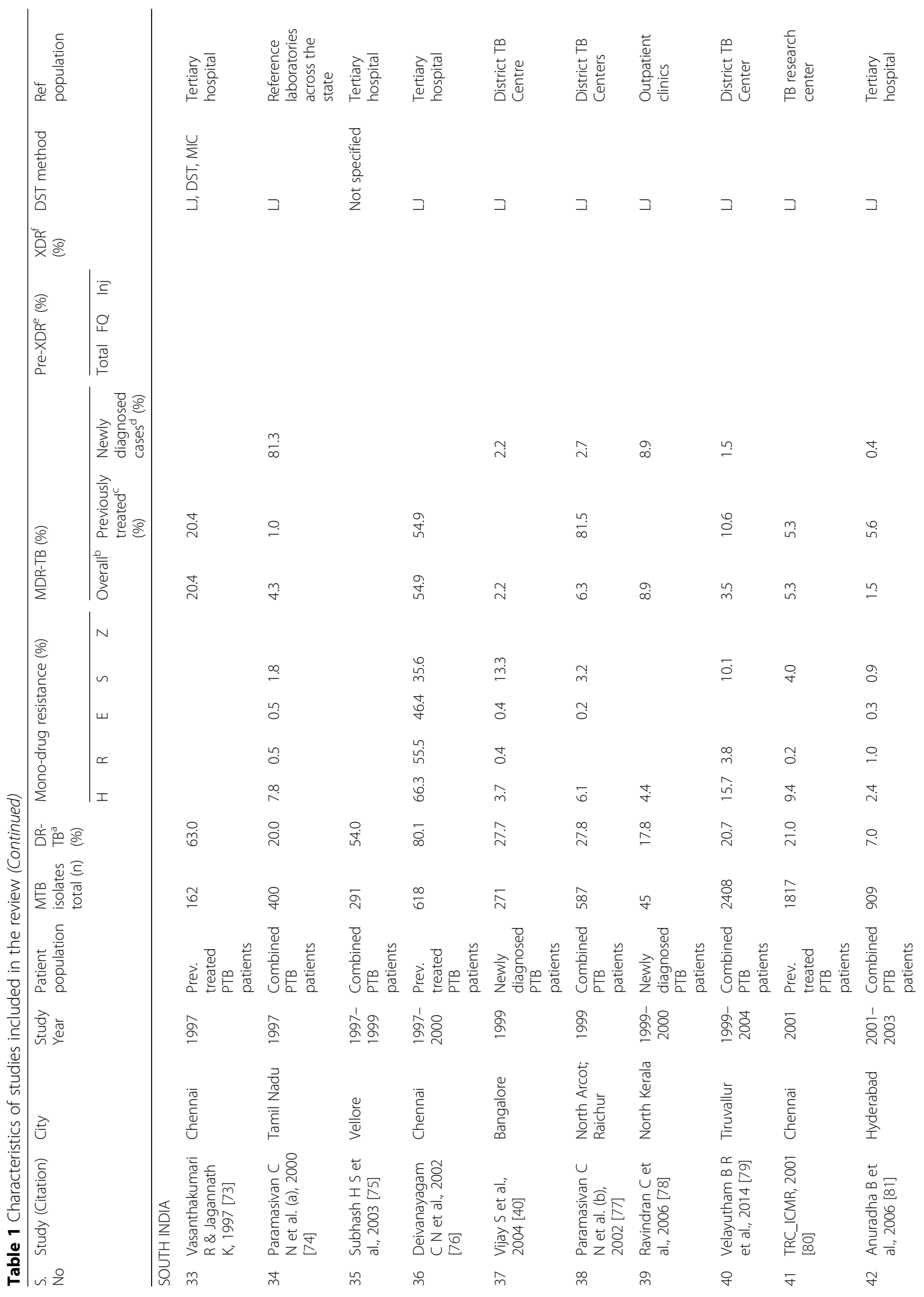




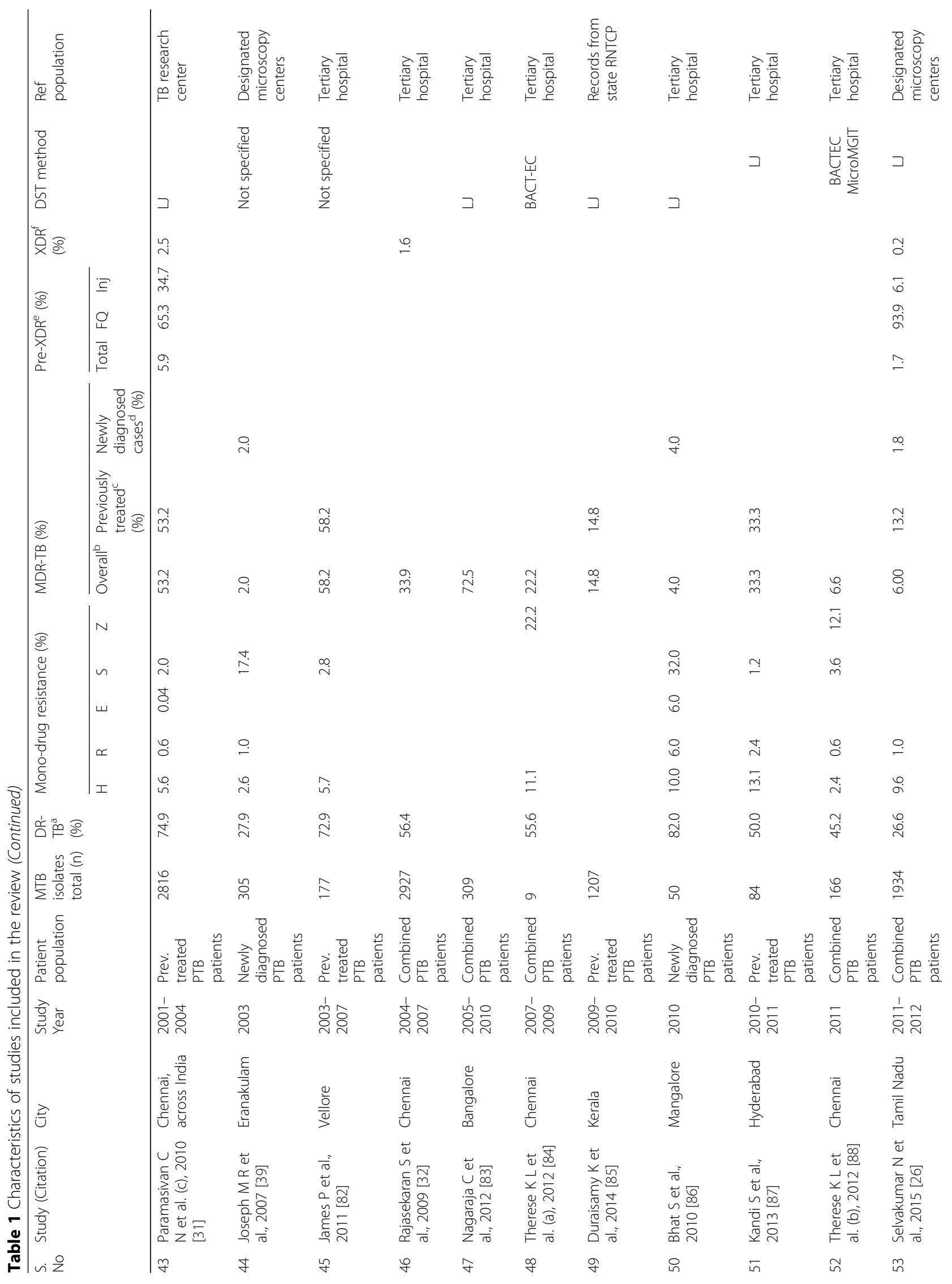




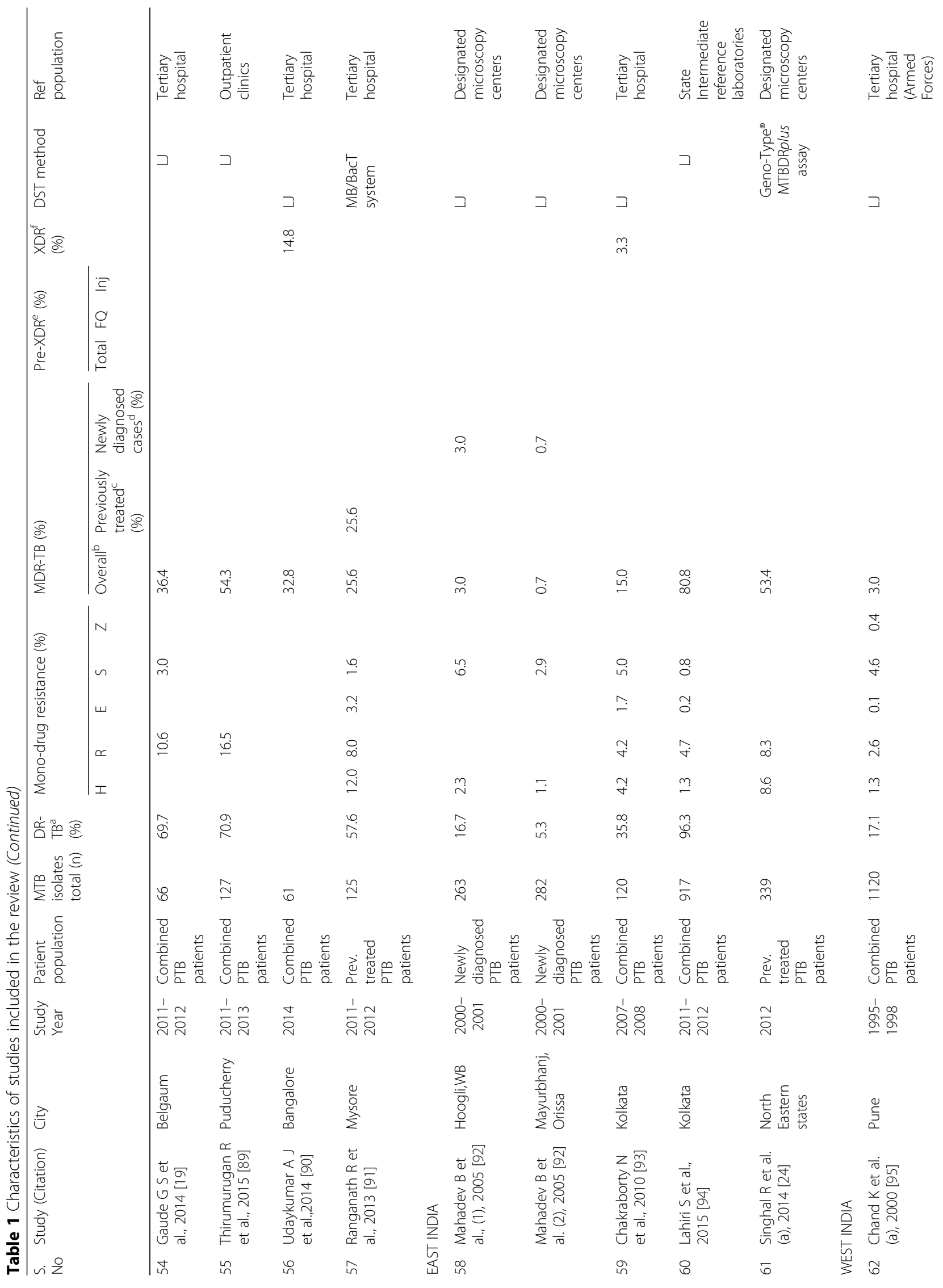




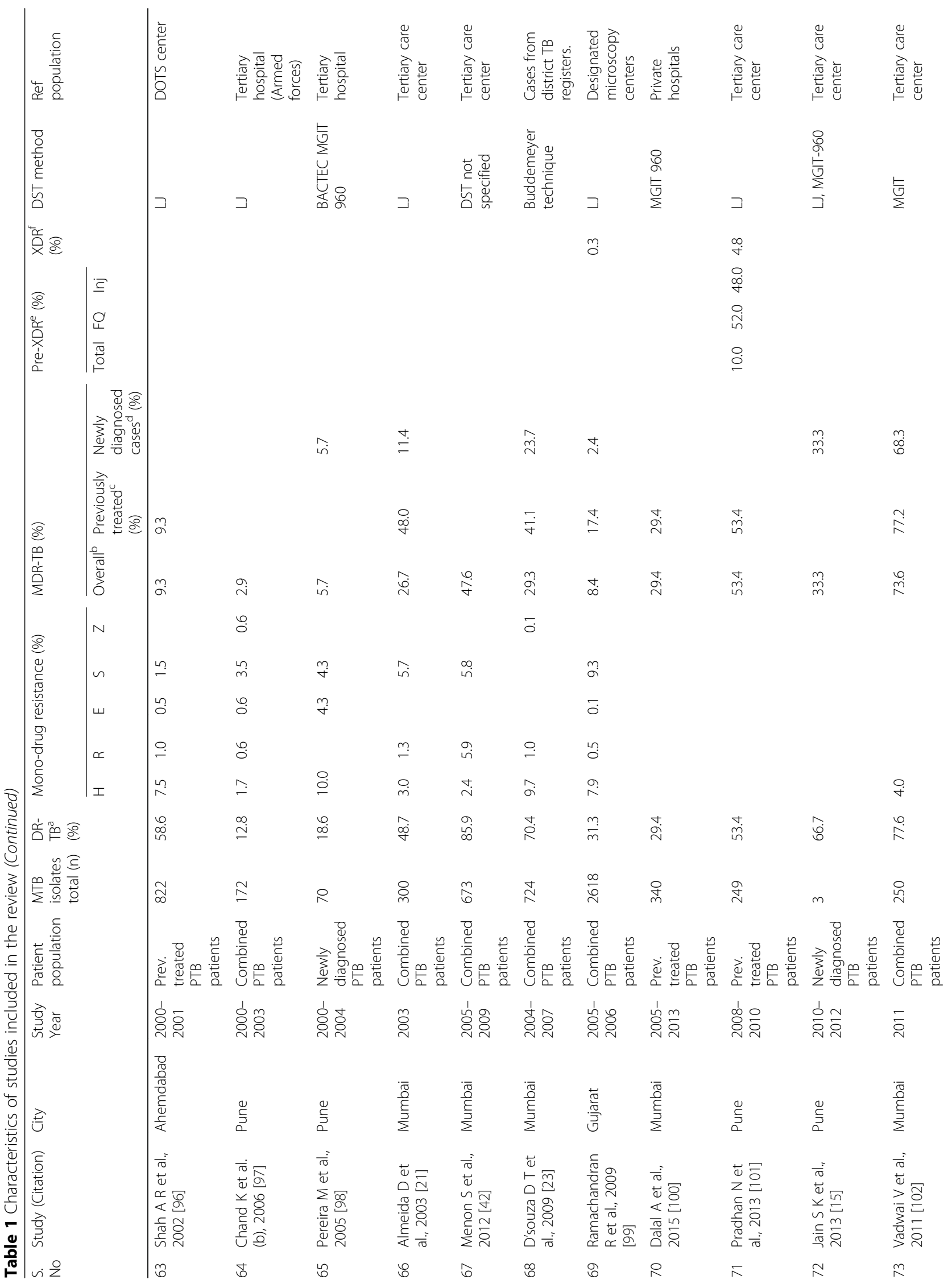




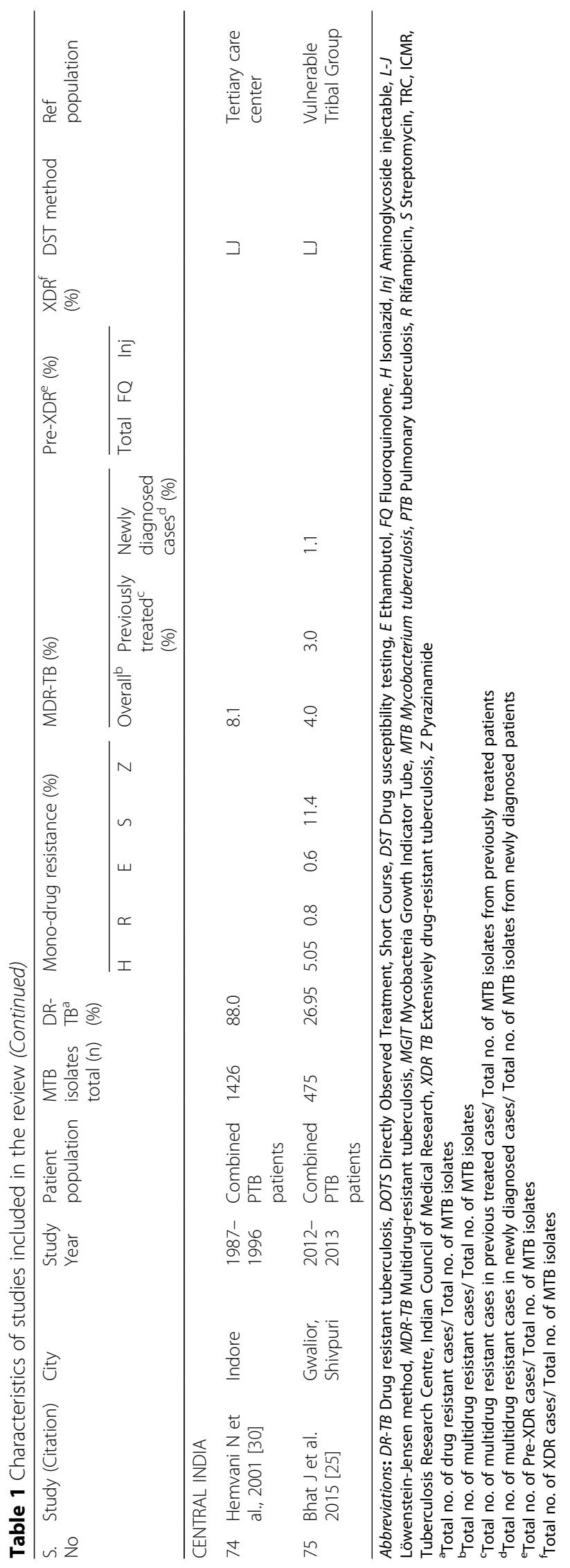



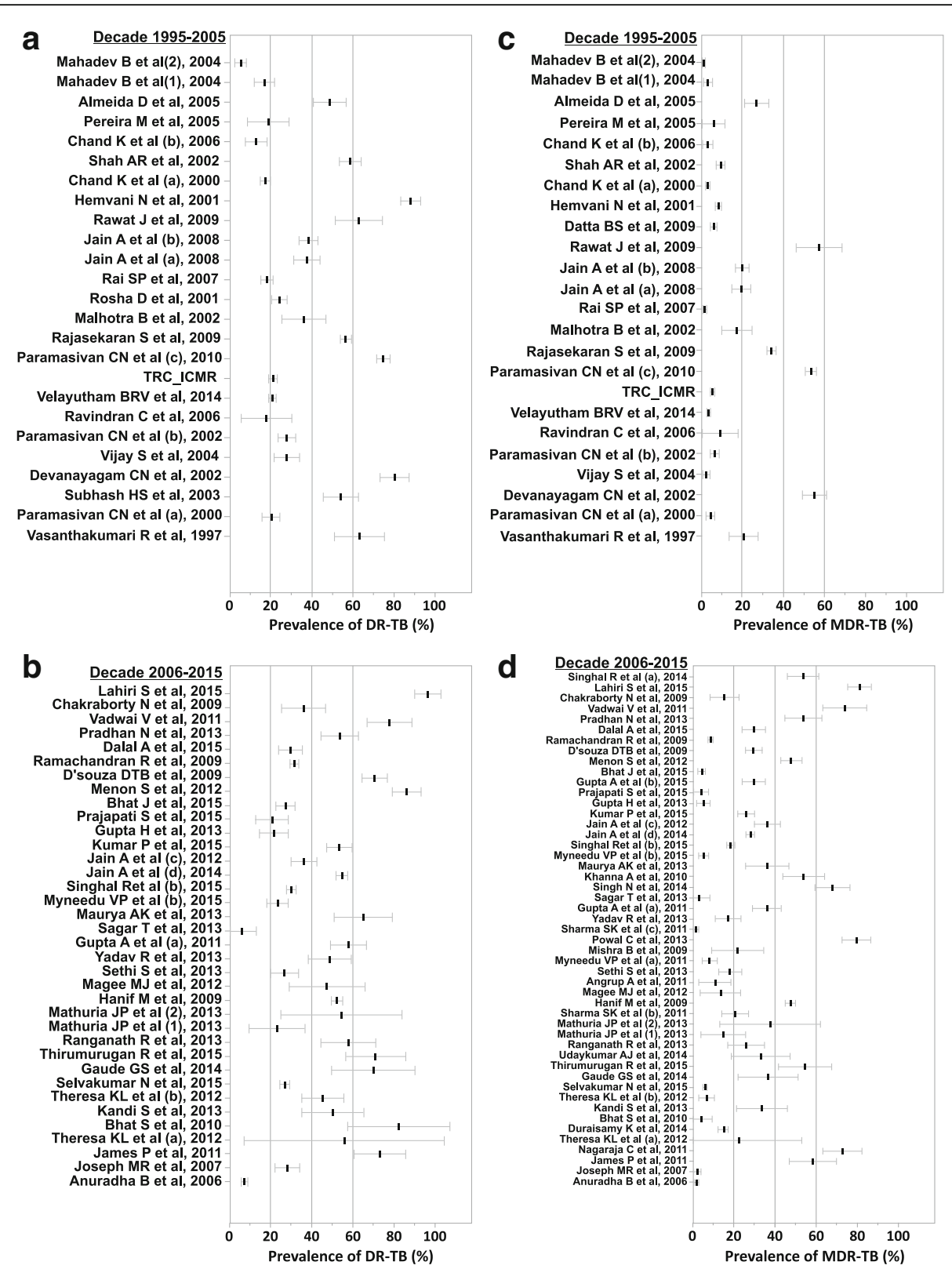

Fig. 2 Forest plot of prevalence of DR-TB and MDR-TB.

(a) Decade 1995-2005 (DR-TB) (b) Decade 2006-2015 (DR-TB) (c) Decade 1995-2005 (MDR-TB) (d) Decade 2006-2015 (MDR-TB). Abbreviations: DR-TB, drug resistant tuberculosis; MDR-TB, multidrug resistant tuberculosis

the highest number of cases for MDR-TB (39.9\% $[95 \% \mathrm{CI}=21.7 ; 58.0, \mathrm{n}=6])$ and South India had the least $(23.2 \%[95 \% \mathrm{CI}=18.2 ; 28.2, n=14])$.

\section{Subgroup analysis (decade and region-wise) for the prevalence of MDR-TB among previously treated and newly diagnosed cases}

Prevalence of MDR-TB was higher among previously treated patients than in newly diagnosed cases in both the decades. For the 20-year period, the countrywide estimates for MDR-TB was 33.7\% (95\% CI = 27.9; 39.5, $n=37)$ among the previously treated patients and $4.8 \%(95 \% \mathrm{CI}=3.7 ; 5.9$, $n=30$ ) among newly diagnosed cases (Table 2).

The countrywide estimates for MDR-TB among previously treated patients was $29.8 \%(95 \% \mathrm{CI}=20.7 ; 39.0$, $n=13)$ in decade 1 and $35.8 \%(95 \% \mathrm{CI}=29.2 ; 42.4$, $n=24)$ in decade 2 . MDR-TB in this population was highest in North India $(33.6 \%$ [95\% CI $=20.9$; 46.3, $n=4])$ and lowest in West India $(28.1 \%[95 \% \mathrm{CI}=-9.8$; 66.1, $n=2]$ ) in the earlier decade (Fig. 4). In decade 2, the western region $(42.8 \%[95 \% \mathrm{CI}=25.8 ; 59.8, n=5])$ 
Table 2 Status of drug-resistant tuberculosis in India

\begin{tabular}{|c|c|c|c|}
\hline$\underline{\text { Drug resistance }}$ & $\mathrm{n}$ & Prevalence estimate (95\% Cl) & Heterogeneity test $\left(l^{2}\right)$ \\
\hline \multicolumn{4}{|l|}{1995 to 2015} \\
\hline Any drug-resistance & 61 & $42.6 \%(37.2 ; 48.0)$ & 14.4 \\
\hline Multidrug resistance & 73 & $23.3 \%(20.5 ; 26.1)$ & 69.2 \\
\hline Previously treated & 37 & $33.7 \%(27.9 ; 39.5)$ & 29.0 \\
\hline Newly diagnosed & 30 & $4.8 \%(3.7 ; 5.9)$ & 79.3 \\
\hline \multicolumn{4}{|l|}{ Mono-drug resistance } \\
\hline Isoniazid & 53 & $7.2 \%(5.9 ; 8.4)$ & 72.5 \\
\hline Streptomycin & 40 & $6.7 \%(5.4 ; 8.0)$ & 67.4 \\
\hline Rifampicin & 42 & $4.6 \%(3.8 ; 5.5)$ & 91.3 \\
\hline Ethambutol & 31 & $1.6 \%(1.2 ; 2.0)$ & 92.0 \\
\hline \multicolumn{4}{|c|}{ Decade 1: 1995 to 2005} \\
\hline Any drug-resistance & 25 & $37.7 \%(29.0 ; 46.4)$ & 10.5 \\
\hline Multidrug resistance & 24 & $14.9 \%(11.0 ; 18.7)$ & 68.4 \\
\hline Previously treated & 13 & $29.8 \%(20.7 ; 39.0)$ & 45.0 \\
\hline Newly diagnosed & 13 & $4.1 \%(2.7 ; 5.6)$ & 70.2 \\
\hline \multicolumn{4}{|l|}{ Mono-drug resistance } \\
\hline Isoniazid & 21 & $8.6 \%(6.2 ; 10.9)$ & 83.7 \\
\hline Streptomycin & 18 & $6.7 \%(5.0 ; 8.5)$ & 81.1 \\
\hline Rifampicin & 15 & $3.6 \%(2.5 ; 4.7)$ & 94.7 \\
\hline Ethambutol & 13 & $1.9 \%(1.2 ; 2.6)$ & 96.1 \\
\hline \multicolumn{4}{|c|}{ Decade 2: 2006 to 2015} \\
\hline Any drug-resistance & 36 & $46.1 \%(39.0 ; 53.2)$ & 9.1 \\
\hline Multidrug resistance & 49 & $27.9 \%(23.8 ; 32.1)$ & 57.1 \\
\hline Previously treated & 24 & $35.8 \%(29.2 ; 42.4)$ & 36.3 \\
\hline Newly diagnosed & 17 & $5.6 \%(3.8 ; 7.4)$ & 82.1 \\
\hline \multicolumn{4}{|l|}{ Mono-drug resistance } \\
\hline Streptomycin & 22 & $6.8 \%(4.8 ; 8.8)$ & 28.7 \\
\hline Isoniazid & 32 & $6.2 \%(5.0 ; 7.5)$ & 24.9 \\
\hline Rifampicin & 27 & $5.1 \%(3.7 ; 6.6)$ & 84.3 \\
\hline Ethambutol & 18 & $1.7 \%(1.0 ; 2.3)$ & 45.2 \\
\hline
\end{tabular}

Cl Confidence interval, $n$ Number of studies

reported highest prevalence of MDR-TB among previously treated patients and southern region reported the lowest $(22.9 \%[95 \% \mathrm{CI}=15.2 ; 30.6, n=6])$.

Among the newly diagnosed cases, the countrywide prevalence was $4.1 \%(95 \% \mathrm{CI}=2.7 ; 5.6, n=13)$ during decade 1 and $5.6 \%(95 \% \mathrm{CI}=3.8 ; 7.4, n=17)$ in decade 2. Highest estimate for MDR-TB was found in the West region (decade 1: 8.7\% [95\% CI $=3.1 ; 14.3, n=2]$; decade 2: $29.4 \%[95 \% \mathrm{CI}=7.5 ; 51.4, n=3])$ and lowest in the South (decade 1: $2.5 \%$ [95\% CI $=0.6 ; 4.4, n=5]$; decade 2: $1.4 \%[95 \% \mathrm{CI}=0.3 ; 2.5, n=4])$ (Fig. 4).

\section{Prevalence of pre-XDR and XDR-TB}

The countrywide prevalence of pre-XDR TB over the 20 -year period was $7.9 \%(95 \% \mathrm{CI}=4.4 ; 11.4, n=5)$. $\mathrm{A}$ majority of these pre-XDR cases was due to resistance to fluoroquinolones (66.3\% [95\% CI $=58.2 ; 74.4, n=5]$ ). Prevalence of XDR-TB was notified in 14 studies and the countrywide prevalence was $(1.9 \%[95 \% \mathrm{CI}=1.2 ; 2.6])$ (Fig. 5). Due to limited data from published studies for pre-XDR and XDR-TB, a subgroup analysis stratified by regions and decades could not be performed.

\section{Subgroup analysis (decade and region-wise) for the prevalence of mono-drug resistance}

The countrywide prevalence of mono-drug resistance revealed the highest rates for isoniazid across the 20-year period $(7.2 \%[95 \% \mathrm{CI}=5.9 ; 8.4, n=53)$ and during decade $1(8.6 \%[95 \% \mathrm{CI}=6.2 ; 10.9, n=21])$. Resistance to streptomycin alone had the highest prevalence during 


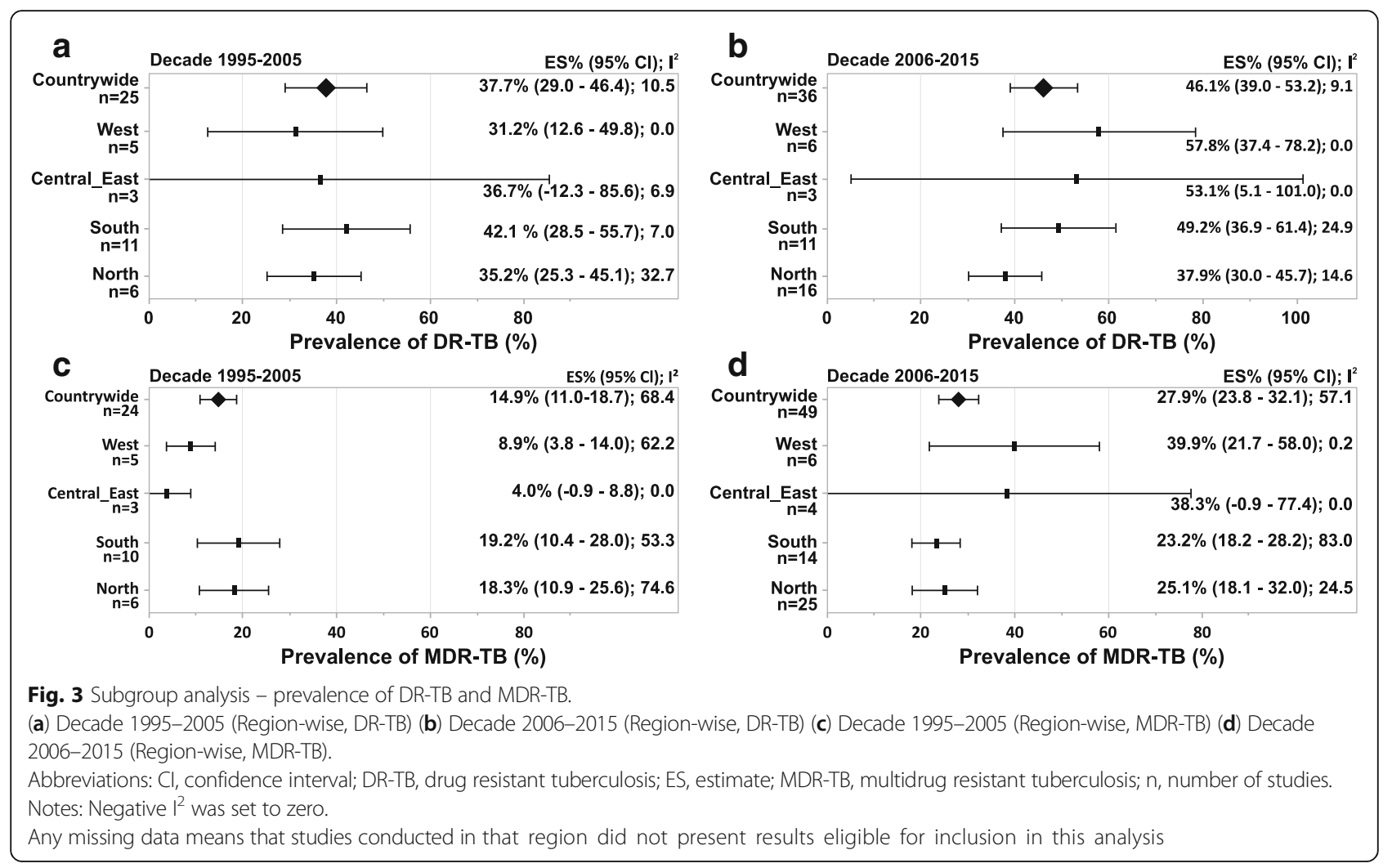

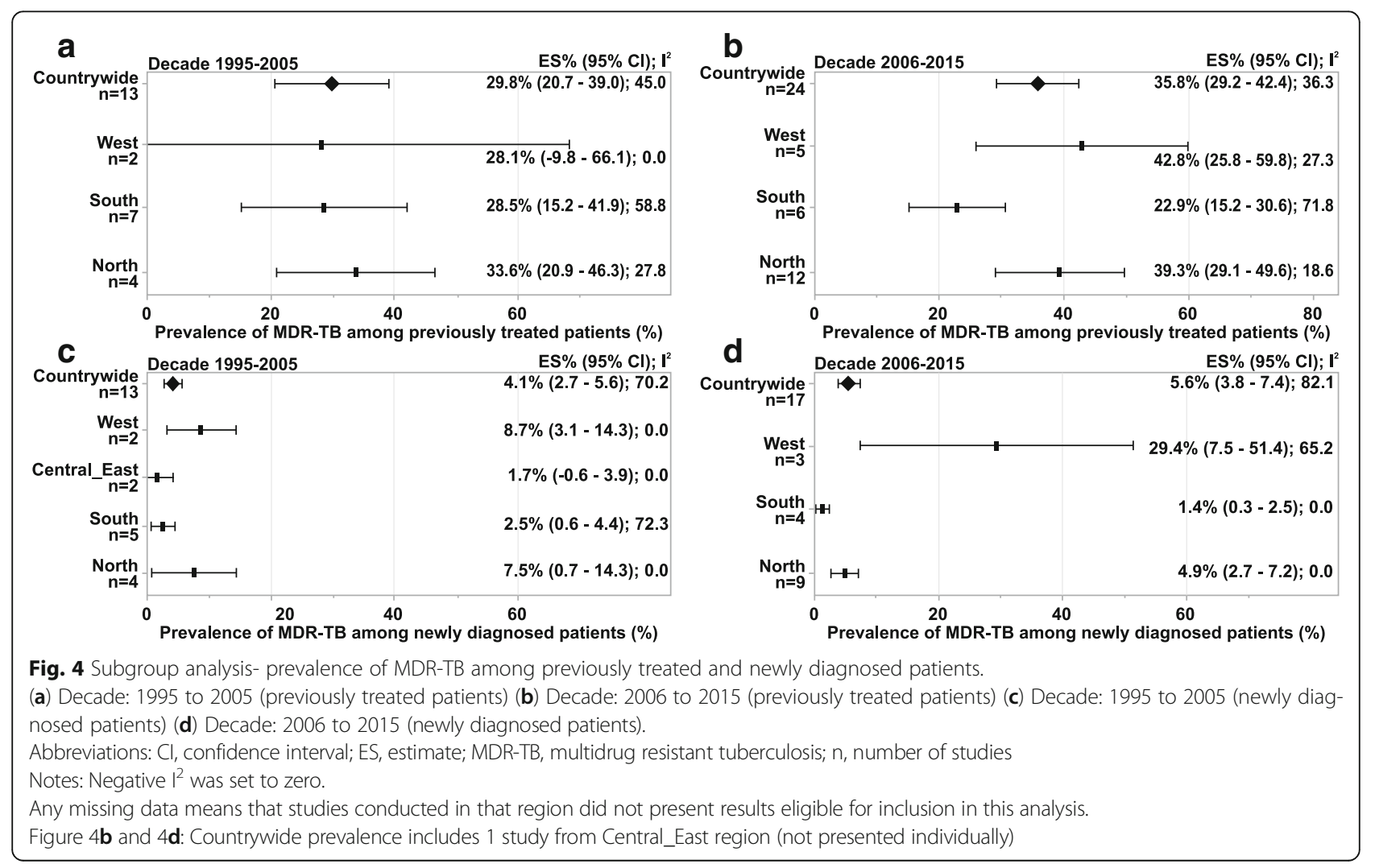



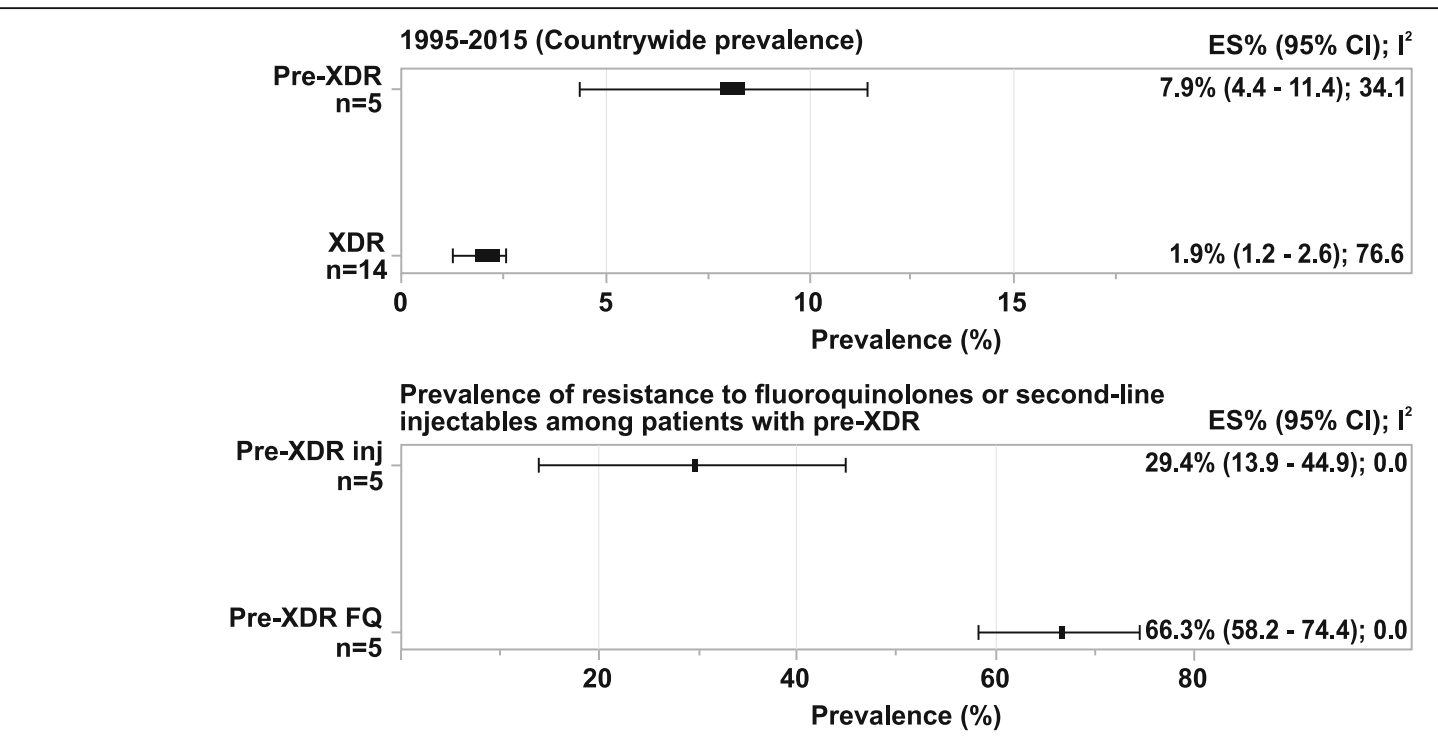

Fig. 5 Subgroup analysis- Countrywide prevalence of Pre-XDR and XDR-TB.

Abbreviations: Cl, confidence interval; ES, estimate; FQ, Fluoroquinolone; Inj, aminoglycoside injectable; XDR-TB, extensively drug-resistant TB; $n$, number of studies.

Notes: Negative $\mathrm{I}^{2}$ was set to zero.

Any missing data means that studies conducted in that region did not present results eligible for inclusion in this analysis

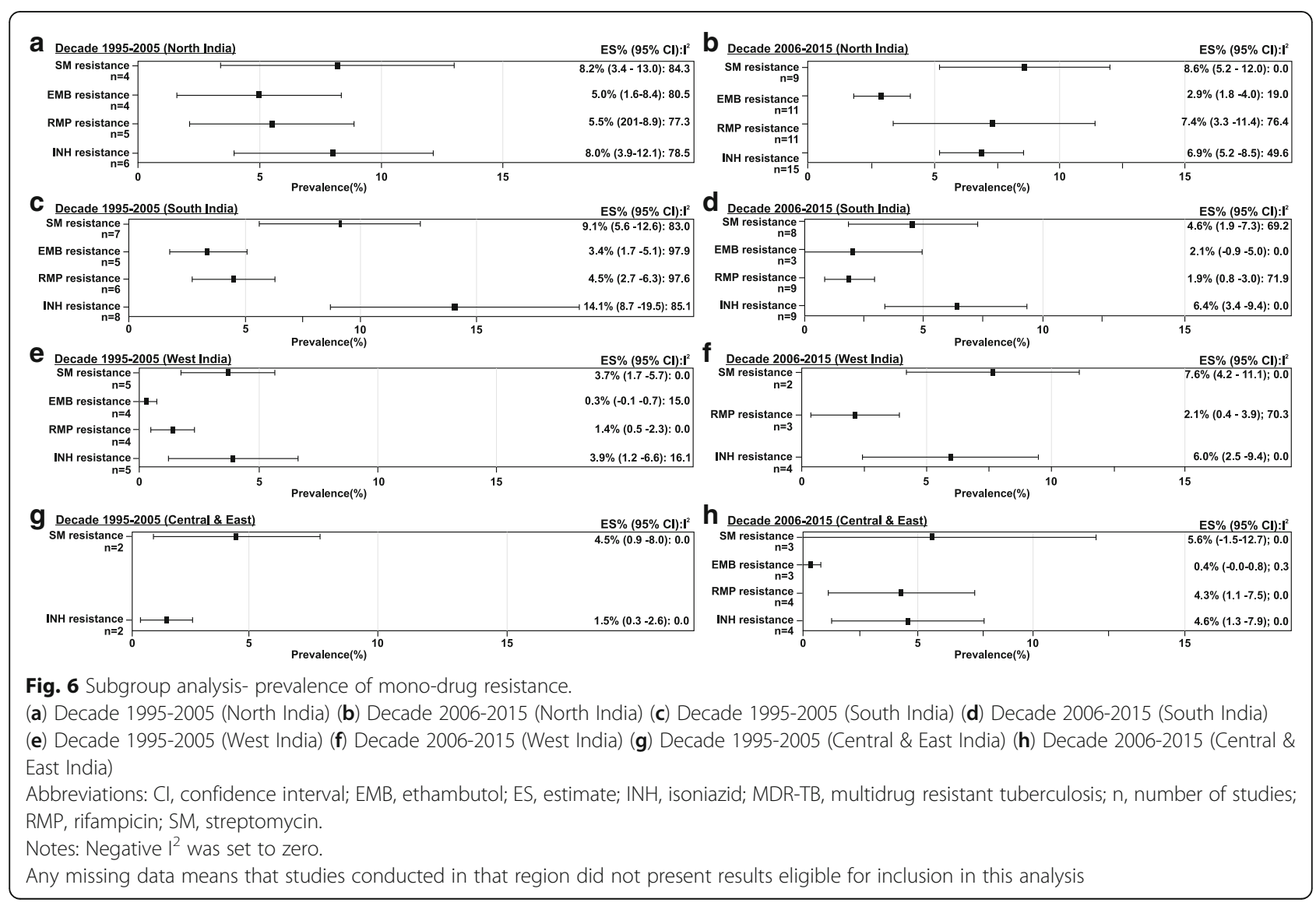


decade 2 (6.8\% [95\% CI $=4.8 ; 8.8, n=22])$. Mono-drug resistance to ethambutol had the lowest prevalence over the 20-year timeframe $(1.6 \%$ [95\% CI $=1.2 ; 2.0, n=31])$, decade $1(1.9 \%$ [95\% CI $=1.2 ; 2.6, n=13])$ as well as decade $2(1.7 \%[95 \% \mathrm{CI}=1.0 ; 2.3, n=18)])$ (Table 2$)$. The country-wide estimates for rifampicin mono-drug resistance were $4.6 \%$ ( $95 \% \mathrm{CI}=3.8 ; 5.5, n=42)$ over the 20-year period, $3.6 \%(95 \% \mathrm{CI}=2.5 ; 4.7, n=15)$ in decade 1 and $5.1 \%(95 \% \mathrm{CI}=3.7 ; 6.6, n=27)$ in decade 2 (Table 2).

Overall, the prevalence estimates for mono-drug resistance to streptomycin and isoniazid were generally high whereas, the prevalence of mono-drug resistance to ethambutol and rifampicin was low across all regions during both decades (Fig. 6).

\section{Discussion}

This systematic review and meta-analysis attempted to demonstrate the geographical distribution of DR-, MDRand XDR-TB and identify the high-risk regions and populations based on an analysis of published studies in India over the past two decades. To the best of our knowledge, the present study is the first to investigate the prevalence of DR-TB in India using systematic review of published studies. Pooled estimates for the countrywide prevalence of DR-TB and MDR-TB revealed a worsening trend between the two study decades. The estimates for MDR-TB subgroups from the present study were higher than the national estimates reported by the RNTCP for the year 2015 (15\%, previously treated cases; $2.2 \%$, newly diagnosed cases) and WHO estimates for India (16\%, previously treated cases; $2.5 \%$, newly diagnosed cases) $[4,7]$. Estimates presented by global or national control programs are based on samples from government centers comprising of potentially susceptible populations or populations where the infection appearance or recurrence is monitored regularly and treated optimally. Therefore, estimates generated from an analysis of these samples may not be a true representation of the TB population in the real-world [16-18]. The present meta-analysis was based on results from published clinical studies conducted pan-India, reporting data for diverse patient populations at varied set-ups that include government tertiary care hospitals (not covered under RNTCP), outpatient clinics, private multispecialty hospitals and district level RNTCP centers. The data therefore, effectively entails regional influences and different epidemiological factors contributing to drug resistance and does not involve selective sampling of patients. However, it should be noted that the prevalence rates reported in the current analysis potentially reflect the status among suspected isolates referred for resistance testing and may not be reflective of prevalence rates of resistance in general, which may be lower.
Interrupted or irregular TB treatments are the strongest determinants for acquired mono-drug resistance and promote the risk of bacterial mutations that eventually culminate in relapses and MDR-TB [19, 20]. Regional analysis for estimates of drug resistance showed that the burden of DR- and MDR-TB in all regions (North, South, West, East and Central) increased over the 20-year period. West India had the lowest prevalence of DR-TB in decade 1 which increased considerably making it the region with the highest number of DR-TB cases in the 2006 to 2015 decade. The prevalence of MDR-TB in this region also increased between the two decades and the prevalence of primary MDR-TB in newly diagnosed smear-positive patients was higher in this region. The 12 studies from West of India included metropolitan cities such as Mumbai, Pune and major cities from Gujarat, highlighting the rapid emergence of DR- and MDR-TB in over-populated urban locales. Increased risk of infection transmission due to crowding, inadequacies in community TB control programs and most importantly, the high variability in the anti-TB treatment regimens prescribed by doctors, particularly in the private sector are some potential factors attributable to this upsurge [21, 22]. High rates of MDR-TB in Mumbai have previously been reported in individual studies involving RNTCP outpatients from municipal wards [23] and patients from a multispecialty private tertiary care hospital [21]. In contrast to the bigger cities in India, the studies in Central and East zones included population from rural and smaller towns. Among other factors, sparse population, access to free and supervised government aided medical centers and limited access to multiple doctors (leading to lesser variability in treatments) can be associated with the relatively lower prevalence of DR- and MDR-TB observed in this zone [21]. However, an overall underreporting of the DR- and MDRTB burden due to difficult geographical terrain that limits accessibility to healthcare resources and poor socioeconomic status should not be overlooked [21, 24, 25].

Resistance to fluoroquinolones among pre-XDR-TB cases had the highest nationwide prevalence as compared with the rates for second-line aminoglycoside injectables. Easy access and indiscriminate use of fluoroquinolone antibiotics for other common non-TB infections are the most predictable risk factors for the development of resistance to these second-line drugs [26-31]. Findings from case studies suggest that shortterm monotherapy with any fluoroquinolone can result in acquisition of resistance in MTB leading to serious implications that include poor MDR-TB treatment outcomes [32, 33]. Although, the estimates for XDR-TB over the 20-year period was low, of concern are the high rates of resistance to fluoroquinolones which have been regarded as one of the risk factors for the emergence of XDR-TB [28, 31, 34, 35]. India's big share $(63 \%)$ in the 
private TB market volume for second-line drugs is another major contributing factor for the high fluoroquinolone resistance observed [36]. Taking into account the minuscular share of the more preferred injectable second-line drugs ( $1 \%$ as opposed to $96 \%$ for fluoroquinolones [along with amoxicillin/clavunate]), fluoroquinolones are most likely to be used as monotherapy or even add-on to first-line anti-TB therapy instead of their recommended use as a second-line drug. Such irregularities in the usage of second-line drugs in private sector result in inadequate treatment for MDR-TB adversely impacting treatment outcomes and emergence of resistance [36, 37].

Mono-drug resistance to isoniazid and streptomycin were recorded at high levels and resistance to ethambutol alone had the least occurrence in India across both decades. Resistance to multiple first-line drugs underscores the importance of the implementation of the quadruple drug regimen for initial phase of tuberculosis treatment as advocated by DOTS [38]. The high levels of streptomycin resistance may be suggestive of its irrational use in non-DOTS treatment regimens at government and private set-ups [17, 39, 40]. Further, analysis of resistant strains have considered mono-drug resistance to isoniazid and streptomycin as factors that drive the development and amplification of additional resistance $[41,42]$.

Overall, these results emphasize on the importance of reinforcing DST in all patients previously exposed to anti-TB drugs to understand the drug resistance pattern and judiciously dispense standard or individualized chemotherapy for resistant cases. There is an impending need to curb the indiscriminate use of second-line drugs and advocate judicious use of newer drugs among physicians at various medical care set-ups to achieve better outcomes in patients with MDR-TB. The high prevalence of MDR-TB reported in the present study signifies the critical gaps in current treatment regimens and the need for fortification with better formulations comprising of newer drugs that have a distinct mode of action. In a country like India, where functioning of healthcare system heavily relies on the private sector, the adoption of newer drugs into government approved standardized regimens should be propagated unanimously and operational activities should be closely monitored for proper execution.

Some limitations of the present analysis should be considered. As the articles included for prevalence estimation did not encompass all states of India, these results may not truly represent the magnitude of DR-TB burden in India and should be interpreted with caution. In addition, the cumulative estimations of prevalence using a random-effect model may not completely invalidate the heterogeneity between studies. There was also a lack of adjustment for potential confounding factors such as socioeconomic status, age, gender etc. that could influence estimates derived from several studies. Further, it should be noted that an assessment of publication bias or selection bias was not performed.

Few noteworthy observations based on the review of published studies include the lack of standardized methods for DST adopted across India. The use of phenotypic and genotypic assays largely varied in public and private set-ups and was contingent on factors such as cost-effectiveness, availability of resources and sustaining infrastructure at various centers across India. This variability in turn introduces several incongruities such as, absence of standard definition of drug resistance and its different types and concerns pertaining to quality control, sensitivity, and reproducibility of results and validity of the laboratory techniques and could potentially affect the estimates from this meta-analysis [34, 43-46]. These observations emphasize the need to promote establishment and expansion of government endorsed laboratories with improved infrastructure that are capable of carrying out high quality, reliable and rapid turnaround DST.

Another grey area identified was the discordant recording of patient or clinical isolate data, which highlights the need for a standardized collection and reporting technique to aid better clinical correlations and decision making in India [47]. Some variables that contributed to these include differences in study durations and treatment strategies adopted across different regions and set-ups [46]. It is a challenge to understand the extent of nonadherence to medications or the quality of drugs taken by the patients since many were not on RNTCP recommended DOTS therapy [16]. The growing private healthcare sector in India is a major area of concern since these establishments involve the use and distribution of huge quantities of anti-TB drugs, with nonstandardized treatment regimens that are not vigilantly supervised for adherence and completion [48]. These practices often lead to treatment interruptions and drug resistance is a consequence. In addition, timely notifications and efficient recording of patient details are regarded as early markers of community TB scenario and greatly support public healthcare programs. Inadequacies in these systems are therefore suggestive of looming danger [49]. In 2012, the Central TB Division (CTD) in collaboration with National Informatics Centre (NIC) initiated the implementation of a web-based application called 'Nikshay' [49]. This application primarily intends to create a robust database of all TB patients across India and enables access of this information to key policy makers, monitoring authorities and researchers who can positively impact treatment outcomes in TB-infected patients. The Government of India has mandated all private and government health 
establishments (outside the coverage of RNTCP) to ensure timely onward communication of patient details for the Nikshay repository [8].

There also exists a dire need for more regulated nationwide DRS based on standard epidemiological methods in India. Currently, sub-national DRS studies have been conducted in Gujarat, Maharashtra and South of India and the RNTCP is in the process of steering a nationwide initiative [8]. The RNTCP jointly with the National Tuberculosis Institute, Bangalore; U.S. Centers for Disease Control and Prevention (CDC) and WHO have constituted a nationwide survey comprising of representative populations of newly diagnosed and previously treated pulmonary TB cases. This initiative is expected to provide estimates that will be more generalizable to the entire nation and assist evaluations against global figures for improved understanding of the overall TB health situation in India.

\section{Conclusions}

The pooled estimates from this study highlight the growing prevalence of DR- and MDR-TB in India that poses a new challenge to its clinical management and public health strategies. Future research involving assessment of clinical drug usage and identification of independent risk factors would be of great significance. Results from such studies along with robust prevalence estimates from the DRS may potentially help strengthen control measures, guide appropriate interventional and follow-up strategies in vulnerable populations and assist overall clinical decision-making.

\section{Abbreviations}

CDC: Centers for Disease Control and Prevention; Cl: Confidence interval; CTD: Central Tuberculosis Division; DOTS: Directly Observed Treatment, Short course; DR-TB: Drug resistant pulmonary tuberculosis; DST: Drug susceptibility testing; HIV: Human immunodeficiency virus; MDR: Multi-drug resistant; MTB: Mycobacterium tuberculosis; NIC: National Informatics Centre; pre-XDR: Pre-extensively drug-resistant; RNTCP: Revised National Tuberculosis Control Programme; RR-TB: Rifampicin-resistant tuberculosis; TB: Tuberculosis; WHO: World Health Organization; XDR: Extensively drug-resistant

\section{Acknowledgements \\ Priya Ganpathy, MPharm, ISMPP CMPP'M and Khushboo Nagdev, PhD (both SIRO Clinpharm Pvt. Ltd) provided medical writing assistance and Sangita Patil, PhD, ISMPP CMPP'M (SIRO Clinpharm Pvt. Ltd) provided editorial support for this manuscript. Sushant Naik, Rahul Choche and Vikesh Shrivastav (SIRO Clinpharm Pvt. Ltd) provided support in the statistical analysis. This support was funded by Janssen India.}

\section{Funding}

The study was funded by Janssen India.

Availability of data and materials

The data is included in the manuscript and tables.

\section{Authors' contributions}

All authors contributed to the conception and design of the study. All authors supported development, critically reviewed the manuscript and approved the final draft. All authors met ICMJE criteria and all those who fulfilled those criteria are listed as authors. All authors had access to the study data and made the final decision about where to publish these data and approved submission to this journal.
Ethics approval and consent to participate

Not applicable.

\section{Consent for publication}

Not applicable.

\section{Competing interests}

Drs. Goyal, Kadam, Narang and Singh are employees of Janssen India and hold company stocks. The authors declare that they have no other competing interests.

\section{Publisher's Note}

Springer Nature remains neutral with regard to jurisdictional claims in published maps and institutional affiliations.

Received: 7 June 2017 Accepted: 20 September 2017

Published online: 17 October 2017

\section{References}

1. Sloan DJ, Lewis JM. Management of multidrug-resistant TB: novel treatments and their expansion to low resource settings. Trans R Soc Trop Med Hyg. 2016;110(3):163-72.

2. Wallis RS, Maeurer M, Mwaba P, Chakaya J, Rustomjee R, Migliori GB, et al. Tuberculosis-advances in development of new drugs, treatment regimens, host-directed therapies, and biomarkers. Lancet Infect Dis. 2016;16(4):e34-46.

3. World Health Organization. The Global Tuberculosis Report: 2015. Geneva, Switzerland: WHO, 2015. http://www.who.int/tb/publications/global_report/ gtbr2015_executive_summary.pdf. Accessed 2016, Jan 18.

4. World Health Organization. The Global Tuberculosis Report: 2016. Geneva, Switzerland: WHO, 2016. http://www.who.int/tb/publications/global_report/ en/. Accessed 2017, Feb 9.

5. Companion Handbook to the WHO Guidelines for the Programmatic Management of Drug-Resistant Tuberculosis. WHO Guidelines Approved by the Guidelines Review Committee: 2014 update. Geneva, Switzerland: WHO, 2014. http://www.who.int/tb/publications/pmdt_companionhandbook/en/. Accessed 2016, Jan 18.

6. Ahuja SD, Ashkin D, Avendano M, Banerjee R, Bauer M, Bayona JN, et al. Multidrug resistant pulmonary tuberculosis treatment regimens and patient outcomes: an individual patient data meta-analysis of 9,153 patients. PLoS Med. 2012;9(8):e1001300

7. Central TB Division. TB India 2016. RNTCP Annual Status Report. New Delhi: Ministry of Health and Family Welfare; 2016. http://www.tbcindia.nic.in/index1. php?lang=1\&level=1\&sublinkid=4160\&lid=2807. Accessed 9 Feb 2017.

8. Central TB Division. TB India 2015. RNTCP Annual Status Report. New Delhi: Ministry of Health and Family Welfare; 2015. http://www.tbcindia.nic.in/index1. php?lang=1\&level=1\&sublinkid=4160\&lid=2807. Accessed 18 Feb 2016.

9. World Health Organization. Guidelines for surveillance of drug resistance in tuberculosis: 2015 update. Geneva: WHO; 2015. http://apps.who.int/iris/ bitstream/10665/174897/1/9789241549134_eng.pdf. Accessed 25 Mar 2016.

10. Nair SA, Raizada N, Sachdeva KS, Denkinger C, Schumacher S, Dewan P, et al. Factors Associated with Tuberculosis and Rifampicin-Resistant Tuberculosis amongst Symptomatic Patients in India: A Retrospective Analysis. PLoS One. 2016;11(2):e0150054.

11. Sachdeva KS, Kumar A, Dewan P, Kumar A, Satyanarayana S. New vision for Revised National Tuberculosis Control Programme (RNTCP): Universal access - "reaching the un-reached". Indian J Med Res. 2012;135(5):690-4.

12. Ayieko J, Abuogi $L$, Simchowitz B, Bukusi EA, Smith AH, Reingold A. Efficacy of isoniazid prophylactic therapy in prevention of tuberculosis in children: a meta-analysis. BMC Infect Dis. 2014;14:91.

13. Lukoye D, Ssengooba W, Musisi K, Kasule GW, Cobelens FG, Joloba M, et al. Variation and risk factors of drug resistant tuberculosis in sub-Saharan Africa: a systematic review and meta-analysis. BMC Public Health. 2015;15:291.

14. Higgins JP, Thompson SG, Deeks JJ, Altman DG. Measuring inconsistency in meta-analyses. BMJ. 2003;327(7414):557-60.

15. Jain SK, Ordonez A, Kinikar A, Gupte N, Thakar M, Mave V, et al. Pediatric tuberculosis in young children in India: a prospective study. Biomed Res Int. 2013;2013:783698.

16. Jain A, Diwakar $P$, Singh U. Declining trend of resistance to first-line antitubercular drugs in clinical isolates of Mycobacterium tuberculosis in a tertiary care north Indian hospital after implementation of revised national Tuberculosis control programme. Indian J Med Microbiol. 2014;32(4):430-3. 
17. Hanif M, Malik S, Dhingra VK. Acquired drug resistance pattern in tuberculosis cases at the State Tuberculosis Centre, Delhi. India. Int J Tuberc Lung Dis. 2009;13(1):74-8.

18. Sharma SK, Kumar S, Saha PK, George N, Arora SK, Gupta D, et al. Prevalence of multidrug-resistant tuberculosis among category II pulmonary tuberculosis patients. Indian J Med Res. 2011;133:312-5.

19. Gaude GS, Hattiholli J, Kumar P. Risk factors and drug-resistance patterns among pulmonary tuberculosis patients in northern Karnataka region. India Niger Med J. 2014;55(4):327-32

20. Kumar P, Kumar P, Balooni V, Singh S. Genetic mutations associated with rifampicin and isoniazid resistance in MDR-TB patients in North-West India. Int J Tuberc Lung Dis. 2015;19(4):434-9.

21. Almeida D, Rodrigues C, Udwadia ZF, Lalvani A, Gothi GD, Mehta P, et al. Incidence of multidrug-resistant tuberculosis in urban and rural India and implications for prevention. Clin Infect Dis. 2003:36(12):e152-4.

22. Uplekar MW, Shepard DS. Treatment of tuberculosis by private general practitioners in India. Tubercle. 1991;72(4):284-90.

23. D'Souza DT, Mistry NF, Vira TS, Dholakia Y, Hoffner S, Pasvol G, et al. High levels of multidrug resistant tuberculosis in new and treatment-failure patients from the Revised National Tuberculosis Control Programme in an urban metropolis (Mumbai) in Western India. BMC Public Health. 2009;9:211.

24. Singhal R, Myneedu VP, Arora J, Singh N, Sah GC, Sarin R. Detection of multi-drug resistance \& characterization of mutations in Mycobacterium tuberculosis isolates from North- Eastern States of India using GenoType MTBDRplus assay. Indian J Med Res. 2014;140(4):501-6.

25. Bhat J, Rao VG, Yadav R, Muniyandi M, Sharma R, Karfarma C, et al. Situation of drug resistant tuberculosis in Saharia tribe of central India. Indian J Med Res. 2015;141(5):636-9.

26. Selvakumar N, Kumar V, Balaji S, Prabuseenivasan S, Radhakrishnan R, Sekar $\mathrm{G}$, et al. High rates of ofloxacin resistance in Mycobacterium tuberculosis among both new and previously treated patients in Tamil Nadu. South India PLoS One. 2015;10(3):e0117421.

27. Rai SP, Bhattacharyya D, Kashyap M. Pattern of initial drug resistance and its impact on short course chemotherapy of pulmonary tuberculosis. Lung India. 2007:24:51-3.

28. Porwal C, Kaushik A, Makkar N, Banavaliker JN, Hanif M, Singla R, et al. Incidence and risk factors for extensively drug-resistant tuberculosis in Delhi region. PLoS One. 2013;8(2):e55299.

29. Jain A, Dixit P, Prasad R. Pre-XDR \& XDR in MDR and Ofloxacin and Kanamycin resistance in non-MDR Mycobacterium tuberculosis isolates. Tuberculosis (Edinb). 2012;92(5):404-6.

30. Hemvani N, Chitnis DS, Bhatia GC, Sharma N. Drug resistance among tubercle bacilli from pulmonary tuberculosis cases in central India. Indian J Med Sci. 2001;55(7):382-92

31. Paramasivan CN, Rehman F, Wares F, Sundar Mohan N, Sundar S, Devi S, et al. First- and second-line drug resistance patterns among previously treated tuberculosis patients in India. Int J Tuberc Lung Dis. 2010;14(2):243-6.

32. Rajasekaran S, Chandrasekar C, Mahilmaran A, Kanakaraj K, Karthikeyan DS, Suriakumar J. HIV coinfection among multidrug resistant and extensively drug resistant tuberculosis patients-a trend. J Indian Med Assoc. 2009; 107(5):281-2. 4-6

33. Mlambo CK, Warren RM, Poswa X, Victor TC, Duse AG, Marais E. Genotypic diversity of extensively drug-resistant tuberculosis (XDR-TB) in South Africa Int J Tuberc Lung Dis. 2008;12(1):99-104.

34. Bloch AB, Cauthen GM, Onorato IM, Dansbury KG, Kelly GD, Driver CR, et al. Nationwide survey of drug-resistant tuberculosis in the United States. JAMA. 1994;271(9):665-71.

35. Thomas A, Joseph P, Nair D, Rao DV, Rekha W, Selvakumar N, et al. Extensively drug-resistant tuberculosis: experience at the Tuberculosis Research Centre, Chennai. India Int J Tuberc Lung Dis. 2011;15(10):1323-5.

36. Wells WA, Ge CF, Patel N, Oh T, Gardiner E, Kimerling ME. Size and usage patterns of private TB drug markets in the high burden countries. PLoS One. 2011;6(5):e18964.

37. Agrawal D, Udwadia ZF, Rodriguez C, Mehta A. Increasing incidence of fluoroquinolone-resistant Mycobacterium tuberculosis in Mumbai. India. Int J Tuberc Lung Dis. 2009;13(1):79-83.

38. Mathuria JP, Samaria JK, Srivastava GN, Mathuria BL, Ojha SK, Anupurba S. Primary and acquired drug resistance patterns of Mycobacterium tuberculosis isolates in India: a multicenter study. J Infect Public Health. 2013;6(6):456-64.

39. Joseph MR, Shoby CT, Amma GR, Chauhan LS, Paramasivan CN. Surveillance of anti-tuberculosis drug resistance in Ernakulam District, Kerala State, South India. Int J Tuberc Lung Dis. 2007;11(4):443-9.
40. Vijay SBV, Jagannatha PS, Kumar P. Initial drug resistance among tuberculosis patients under DOTS programme in bangalore city. Indian Journal of Tuberculosis. 2004;51:17-21.

41. Paramasivan CN, Venkataraman P. Drug resistance in tuberculosis in India. Indian J Med Res. 2004;120(4):377-86.

42. Menon S, Dharmshale S, Chande C, Gohil A, Lilani S, Mohammad S, et al. Drug resistance profiles of Mycobacterium tuberculosis isolates to first line anti-tuberculous drugs: A five years study. Lung India. 2012; 29(3):227-31.

43. Martin A, Portaels F, Palomino JC. Colorimetric redox-indicator methods for the rapid detection of multidrug resistance in Mycobacterium tuberculosis: a systematic review and meta-analysis. J Antimicrob Chemother. 2007;59(2): 175-83.

44. Stagg HR, Brown J, Ibraim E, Riekstina V, Viiklepp P, Cirule A, et al. Drug Susceptibility Patterns in MDR-TB Patients: Challenges for Future Regimen Design. A Cross-Sectional Study PLoS One. 2015;10(11):e0142425.

45. Maurya AK, Umrao J, Singh AK, Kant S, Kushwaha RA, Dhole TN. Evaluation of GenoType(R) MTBDRplus assay for rapid detection of drug susceptibility testing of multi-drug resistance tuberculosis in Northern India. Indian J Pathol Microbiol. 2013;56(2):139-43.

46. Migliori GB, Matteelli A, Cirillo D, Pai M. Diagnosis of multidrug-resistant tuberculosis and extensively drug-resistant tuberculosis: Current standards and challenges. Can J Infect Dis Med Microbiol. 2008;19(2):169-72.

47. Orenstein EW, Basu S, Shah NS, Andrews JR, Friedland GH, Moll AP, et al. Treatment outcomes among patients with multidrug-resistant tuberculosis: systematic review and meta-analysis. Lancet Infect Dis. 2009;9(3):153-61.

48. Nagpal M, Chawla N. Tuberculosis Notification: Issues and Challenges. Online Journal of Health and Allied Sciences. 2013:12(2):1-2.

49. RNTCP. Guidance for TB Notification in India. In: Central TB Division DGoHS, editor. 2012. Available online: http://www.tbcindia.nic.in/index1.php?lang= $1 \&$ level=1\&sublinkid=4529\&lid=3135. Accessed 18 Jan 2016

50. Malhotra B, Pathak S, Vyas L, Katoch VM, Srivastava K, Chauhan DS, et al. Drug susceptibility profiles of Mycobacterium tuberculosis isolates at Jaipur. Indian J Med Microbiol. 2002;20(2):76-8.

51. Sharma SK, George N, Kadhiravan T, Saha PK, Mishra HK, Hanif M. Prevalence of extensively drug-resistant tuberculosis among patients with multidrugresistant tuberculosis: a retrospective hospital-based study. Indian J Med Res. 2009:130(4):392-5.

52. Rosha D, Kataria V. Impact of initial drug resistance pattern on the Maintenance phase of short course chemotherapy with Reference to the emergence of multi drug resistance. Indian J Tuberc. 2001;48:205-7.

53. Jain A, Mondal R, Srivastava S, Prasad R, Singh K, Ahuja RC. Novel mutations in emb $B$ gene of ethambutol resistant isolates of Mycobacterium tuberculosis: a preliminary report. Indian J Med Res. 2008;128(5):634-9.

54. Jain A, Mondal R, Prasad R, Singh K, Ahuja RC. Prevalence of multidrug resistant Mycobacterium tuberculosis in Lucknow. Uttar Pradesh Indian J Med Res. 2008;128(3):300-6.

55. Rawat J, Sindhwani G, Juyal R, Dua R. Five-year trend of acquired antitubercular drug resistance in patients attending a tertiary care hospital at Dehradun (Uttarakhand). Lung India. 2009;26(4):106-8.

56. Datta BS, Hassan G, Kadri SM, Qureshi W, Kamili MA, Singh H, et al. Multidrug-resistant and extensively drug resistant tuberculosis in Kashmir. India J Infect Dev Ctries. 2010:4(1):19-23.

57. Magee MJ, Blumberg HM, Broz D, Furner SE, Samson L, Singh S, et al. Prevalence of drug resistant tuberculosis among patients at high-risk for Hiv attending outpatient clinics in Delhi, India. Southeast Asian J Trop Med Public Health. 2012;43(2):354-63.

58. Angrup A, Varma-Basil M, Kumar S, Pathak RK, Sharma H, Banavaliker JN, et al. Drug resistance among Mycobacterium tuberculosis isolates from private clinics and a dots center in Delhi, India. Southeast Asian J Trop Med Public Health. 2011;42(1):122-7.

59. Sethi S, Mewara A, Dhatwalia SK, Singh H, Yadav R, Singh $K$, et al. Prevalence of multidrug resistance in Mycobacterium tuberculosis isolates from HIV seropositive and seronegative patients with pulmonary tuberculosis in north India. BMC Infect Dis. 2013;13:137.

60. Myneedu VP, Visalakshi P, Verma AK, Behera D, Bhalla M. Prevalence of XDR TB cases-a retrospective study from a tertiary care TB hospital. Indian J Tuberc. 2011:58(2):54-9.

61. Mishra JKSD, Anupurbam S, Mishra RN, Mohapatra SC. Pattern of drug resistance in tuberculosis patients attending tertiary care hospital, Varanasi Indian. J Prev Soc Med. 2009;40:1-2. 
62. Sharma SK, Kaushik G, Jha B, George N, Arora SK, Gupta D, et al. Prevalence of multidrug-resistant tuberculosis among newly diagnosed cases of sputum-positive pulmonary tuberculosis. Indian J Med Res. 2011;133:308-11.

63. Yadav R, Sethi S, Dhatwalia SK, Gupta D, Mewara A, Sharma M. Molecular characterisation of drug resistance in Mycobacterium tuberculosis isolates from North India. Int J Tuberc Lung Dis. 2013;17(2):251-7.

64. Gupta A, Mathuria JP, Singh SK, Gulati AK, Anupurba S. Antitubercular drug resistance in four healthcare facilities in North India. J Health Popul Nutr. 2011;29(6):583-92.

65. Sagar T, Singh NP, Kashyap B, Kaur IR. Current status of multidrug resistant tuberculosis in a tertiary care hospital of East Delhi. J Postgrad Med. 2013; 59(3):173-6.

66. Singh N, Sidiq Z, Bhalla M, Myneedu VP, Sarin R. Multi-drug resistant tuberculosis among category I treatment failures-a retrospective study. Indian J Tuberc. 2014;61(2):148-51.

67. Khanna A, Raj VS, Tarai B, Sood R, Pareek PK, Upadhyay DJ, et al. Emergence and molecular characterization of extensively drug-resistant Mycobacterium tuberculosis clinical isolates from the Delhi Region in India. Antimicrob Agents Chemother. 2010;54(11):4789-93.

68. Myneedu VP, Singhal R, Khayyam KU, Sharma PP, Bhalla M, Behera D, et al. First and second line drug resistance among treatment naive pulmonary tuberculosis patients in a district under Revised National Tuberculosis Control Programme (RNTCP) in New Delhi. J Epidemiol Glob Health. 2015; 5(4):365-73

69. Singhal R, Myneedu VP, Arora J, Singh N, Bhalla M, Verma A, et al. Early detection of multi-drug resistance and common mutations in Mycobacterium tuberculosis isolates from Delhi using GenoType MTBDRplus assay. Indian J Med Microbiol. 2015;33(Suppl):46-52.

70. Gupta H, Kant S, Jain A, Natu SM, Ahluwalia S. Initial drug resistance pattern among pulmonary tuberculosis patients. Indian J Tuberc. 2013;60(3):154-61.

71. Prajapati S, Upadhyay K, Mukherjee A, Kabra SK, Lodha R, Singh V, et al. High prevalence of primary drug resistance in children with intrathoracic tuberculosis in India. Paediatr Int Child Health. 2016;36(3):214-8.

72. Gupta A, Singh SK, Anupurba S. Mutations at embB306 codon and their association with multidrug resistant M. tuberculosis clinical isolates. Indian J Med Microbiol. 2015;33(3):387-92.

73. Vasanthakumari R, Jagannath K. Multidrug resistant tuberculosis- A Tamil Nadu study. Lung India. 1997;XV(4):178-80.

74. Paramasivan C, Bhaskariar P, Venkataraman P, Chandrasekaran V, Narayanan $P$. Surveillance of drug resistance in tuberculosis in the state of Tamil Nadu. Indian J Tuberc. 2000;47:27-33.

75. Subhash HS, Ashwin I, Mukundan U, Danda D, John G, Cherian AM, et al. Drug resistant tuberculosis in diabetes mellitus: a retrospective study from south India. Trop Dr. 2003;33(3):154-6.

76. Deivanayagam CN, Rajasekaran S, Venkatesan R, Mahilmaran A, Ahmed PR, Annadurai S, et al. Prevalence of acquired MDR-TB and HIV co-infection. Indian J Chest Dis Allied Sci. 2002:44(4):237-42.

77. Paramasivan CN, Venkataraman P, Chandrasekaran V, Bhat S, Narayanan PR. Surveillance of drug resistance in tuberculosis in two districts of South India. Int J Tuberc Lung Dis. 2002;6(6):479-84.

78. Ravindran C, James P, Jyothi E. Prevalence of initial drug resistance of mycobacterium tuberculosis in Northern Kerala. Lung India. 2006;23:106-8.

79. Velayutham BR, Nair D, Chandrasekaran V, Raman B, Sekar G, Watson B, et al. Profile and response to anti-tuberculosis treatment among elderly tuberculosis patients treated under the TB Control programme in South India. PLoS One. 2014;9(3):e88045.

80. Low rate of emergence of drug resistance in sputum positive patients treated with short course chemotherapy. Int J Tuberc Lung Dis. 2001;5(1):40-5.

81. Anuradha B, Aparna S, Hari Sai Priya V, Vijaya Lakshmi V, Akbar Y, Suman Latha $\mathrm{G}$, et al. Prevalence of drug resistance under the DOTS strategy in Hyderabad, South India, 2001-2003. Int J Tuberc Lung Dis. 2006;10(1):58-62.

82. James P, Gupta R, Christopher DJ, Thankagunam B, Veeraraghavan B. MDRand XDR-TB among suspected drug-resistant TB patients in a tertiary care hospital in India. Clin Respir J. 2011;5(1):19-25.

83. Nagaraja C, Shashibhushan BL, Asif M, Manjunath PH, Sagar C. Pattern of drug-resistance and treatment outcome in multidrug-resistant pulmonary tuberculosis. Indian J Chest Dis Allied Sci. 2012;54(1):23-6.

84. Therese KL, Gayathri R, Balasubramanian S, Natrajan S, Madhavan HN. Phenotypic and genotypic characteristics of drug resistance in Mycobacterium tuberculosis isolates from pediatric population of Chennai. India Indian J Med Microbiol. 2012;30(4):411-7.
85. Duraisamy K, Mrithyunjayan S, Ghosh S, Nair SA, Balakrishnan S, Subramoniapillai J, et al. Does Alcohol consumption during multidrugresistant tuberculosis treatment affect outcome?. A population-based study in Kerala, India. Ann Am Thorac Soc. 2014;11(5):712-8.

86. Bhat S, Radhakrishna M, Kotian M, Rao S. Drug susceptibility profiles of Mycobacterium tuberculosis isolates at Mangalore. Indian J Med Sci. 2010; 64(3):99-103.

87. Kandi S, Prasad SV, Sagar Reddy PN, Reddy VC, Laxmi R, Kopuu D, et al. Prevalence of multidrug resistance among retreatment pulmonary tuberculosis cases in a tertiary care hospital, Hyderabad. India Lung India. 2013;30(4):277-9.

88. Therese KL, Gayathri R, Dhanurekha L, Sridhar R, Meenakshi N, Madhavan $\mathrm{HN}$, et al. Detection of Mycobacterium tuberculosis directly from sputum specimens \& phenotypic drug resistance pattern of $\mathrm{M}$. tuberculosis isolates from suspected tuberculosis patients in Chennai. Indian J Med Res. 2012; 135(5):778-82

89. Thirumurugan R, Kathirvel M, Vallayyachari K, Surendar K, Samrot AV, Muthaiah M. Molecular analysis of rpoB gene mutations in rifampicin resistant Mycobacterium tuberculosis isolates by multiple allele specific polymerase chain reaction in Puducherry. South India J Infect Public Health. 2015;8(6):619-25.

90. Udaykumar A, Jayashree R, Mishra B, Vivek R, Kenneth J. Drug resistance patterns in new and previously treated patients with tuberculosis presenting to a tertiary care center in southern India. BMC Infect Dis. 2014;14(Suppl 3):03.

91. Ranganath R, Kumar VG, Ranganath R, Goud G, Javali V. Drug Resistance Pattern of MTB Isolates from PTB Patients. Tuberc Res Treat. 2013;2013: 862530.

92. Mahadev B, Kumar P, Agarwal S, Chauhan L, Srikantaramu N. Surveillance of drug resistance to anti-tuberculosis drugs in districts of Hoogli in West Bengal and Mayurbhanj in Orissa. Indian J Tuberc. 2005;52:5-10.

93. Chakraborty N, De C, Bhattacharyya S, Mukherjee A, Santra S, Banerjee D, et al. Drug susceptibility profile of Mycobacterium tuberculosis isolated from HIV infected and uninfected pulmonary tuberculosis patients in eastern India. Trans R Soc Trop Med Hyg. 2010;104(3):195-201.

94. Lahiri S, Mukherjee A, Hazra S, Jana P, Roy S, Saha BK. First-line antitubercular drug resistance of mycobacterial strains from re-treatment cases that were smear-positive at 4(th) month onwards under the Revised National Tuberculosis Control Program. Lung India. 2015;32(2):127-31.

95. Kailash C, Tewari SC. Prevalence of drug resistant tuberculosis in armed forces-study from a tertiary referal chest diseases hospital at Pune. Medical Journal Armed Forces India. 2000;56(2):130-4.

96. Shah AR, Agarwal SK, Shah KV. Study of drug resistance in previously treated tuberculosis patients in Gujarat. India. Int J Tuberc Lung Dis. 2002; 6(12):1098-101.

97. Chand K, Khandelwal R, Vardhan V. Resistance to Antituberculosis Drugs in Pulmonary Tuberculosis. Medical Journal Armed Forces India. 2006;62:325-7.

98. Pereira MTS, Inamdar V, Ramesh K, Bhavsar M, Date A, lyyer R, Acchammachary A, Mehendale S, Risbud A. Drug resistance pattern of Mycobacterium tuberculosis in seropositive and seronegative HIV-TB patients in Pune, India. Indian J Med Res. 2005;121:235-9.

99. Ramachandran R, Nalini S, Chandrasekar V, Dave PV, Sanghvi AS, Wares F. et al. Surveillance of drug-resistant tuberculosis in the state of Gujarat. India. Int J Tuberc Lung Dis. 2009;13(9):1154-60.

100. Dalal A, Pawaskar A, Das M, Desai R, Prabhudesai P, Chhajed P, et al. Resistance patterns among multidrug-resistant tuberculosis patients in greater metropolitan Mumbai: trends over time. PLoS One. 2015;10(1): e0116798.

101. Pradhan NDS, Kagal A, Dharmashale S, Bharadwaj R, Ghorpade S, Gaikwad S, Kulkarni V, Gupte N, Bollinger R, Gupta A, Mave V. Patterns of TB DrugResistance in a Tertiary Care Facility in Pune. India Clinical Microbiology. 2013;2(6):123.

102. Vadwai $V$, Shetty A, Soman $R$, Rodrigues $C$. Determination of risk factors for isoniazid monoresistance and multidrug-resistant tuberculosis in treatment failure patients. Scand J Infect Dis. 2012;44(1):48-50. 